\title{
Optogenetic Interrogation of Functional Synapse Formation by Corticospinal Tract Axons in the Injured Spinal Cord
}

\author{
Naveen Jayaprakash, Zimei Wang, Brian Hoeynck, Nicholas Krueger, Audra Kramer, Eric Balle, Daniel S. Wheeler, \\ Robert A. Wheeler, and Murray G. Blackmore \\ Department of Biomedical Sciences, Marquette University, Milwaukee, Wisconsin 53201
}

To restore function after injury to the CNS, axons must be stimulated to extend into denervated territory and, critically, must form functional synapses with appropriate targets. We showed previously that forced overexpression of the transcription factor Sox11 increases axon growth by corticospinal tract (CST) neurons after spinal injury. However, behavioral outcomes were not improved, raising the question of whether the newly sprouted axons are able to form functional synapses. Here we developed an optogenetic strategy, paired with single-unit extracellular recordings, to assess the ability of Sox11-stimulated CST axons to functionally integrate in the circuitry of the cervical spinal cord. Initial time course experiments established the expression and function of virally expressed Channelrhodopsin (ChR2) in CST cell bodies and in axon terminals in cervical spinal cord. Pyramidotomies were performed in adult mice to deprive the left side of the spinal cord of CST input, and the right CST was treated with adeno-associated virus (AAV)-Sox11 or AAV-EBFP control, along with AAV-ChR2. As expected, Sox11 treatment caused robust midline crossing of CST axons into previously denervated left spinal cord. Clear postsynaptic responses resulted from optogenetic activation of CST terminals, demonstrating the ability of Sox11-stimulated axons to form functional synapses. Mapping of the distribution of CST-evoked spinal activity revealed overall similarity between intact and newly innervated spinal tissue. These data demonstrate the formation of functional synapses by Sox11-stimulated CST axons without significant behavioral benefit, suggesting that new synapses may be mistargeted or otherwise impaired in the ability to coordinate functional output.

Key words: axon regeneration; optogenetics; Sox11; spinal cord; synapse; transcription factor

\section{Significance Statement}

As continued progress is made in promoting the regeneration of CNS axons, questions of synaptic integration are increasingly prominent. Demonstrating direct synaptic integration by regenerated axons and distinguishing its function from indirect relay circuits and target field plasticity have presented technical challenges. Here we force the overexpression of Sox 11 to stimulate the growth of corticospinal tract axons in the cervical spinal cord and then use specific optogenetic activation to assess their ability to directly drive postsynaptic activity in spinal cord neurons. By confirming successful synaptic integration, these data illustrate a novel optogenetic-based strategy to monitor and optimize functional reconnection by newly sprouted axons in the injured CNS.

\section{Introduction}

Damage to the CNS disrupts function in part by severing axons, which display little innate ability to regenerate and restore lost

\footnotetext{
Received Nov. 18, 2015; revised March 21, 2016; accepted April 8, 2016.

Author contributions: N.J., A.K., D.S.W., R.A.W., and M.G.B. designed research;N.J., Z.W., B.H., N.K., A.K., and E.B. performed research; N.J., B.H., N.K., A.K., E.B., D.S.W., R.A.W., and M.G.B. analyzed data; N.J., R.A.W., and M.G.B. wrote the paper.

This work was supported by grants from National Institute of Neurological Disorders and Stroke, the International Spinal Research Trust, and the Bryon Riesch Paralysis Foundation. We thank Jacob Riesch and Dr. Marieke Gilmartin for technical assistance

The authors declare no competing financial interests.

Correspondence should be addressed to Murray G. Blackmore, Department of Biomedical Sciences, Marquette University, Milwaukee, WI 53201. E-mail: murray.blackmore@marquette.edu.

DOI:10.1523/JNEUROSCI.4203-15.2016

Copyright $\odot 2016$ the authors $\quad 0270-6474 / 16 / 365877-14 \$ 15.00 / 0$
}

connections. Promising strategies have emerged to promote axon growth, including cell transplantation ( $\mathrm{Lu}$ et al., 2014a), neurotropic factors (Weishaupt et al., 2014), tissue bridges (Wu et al., 2015), neutralization of growth inhibitory molecules (Bradbury and Carter, 2011; Akbik et al., 2012; Fink et al., 2015), and genetic modulation of the neuron-intrinsic growth capacity (Moore et al., 2009; Liu et al., 2010; Blackmore et al., 2012; Du et al., 2015; Wang et al., 2015). Functional recovery requires that axon growth be accompanied by the formation of effective synapses in appropriate target fields. In some cases, behavioral improvements have been observed, hinting at synaptic integration (Houle and Côté, 2013; Liu et al., 2015; Zou et al., 2015). However, behavioral gains are often modest, and it can be unclear whether they result from direct synaptic input from newly grown axons, as 
opposed to plasticity in the target field or in upstream relays (Onifer et al., 2011). In other cases, behavioral effects are undetectable or even negative (Takeoka et al., 2011; Lu et al., 2014b; Geoffroy et al., 2015). For example, we found that overexpression of Sox11, a pro-regenerative transcription factor, improves corticospinal axon growth in the injured spinal cord but that behavioral outcomes were neutral in some tasks and slightly worsened in others (Wang et al., 2015). Such suboptimal behavioral outcomes highlight the need to more directly assess the degree to which axons stimulated to grow, particularly those stimulated by genetic manipulation, and retain the essential ability to form functional synapses with target cells.

Functional synaptogenesis is often assessed indirectly by immunohistochemistry for synaptic proteins (Liu et al., 2010; Lu et al., 2014b; Du et al., 2015; Wu et al., 2015), but this approach can be only suggestive in regards to function. Alternatively, electrical or magnetic stimulation of cell bodies is paired with monitoring of muscle activity in distal targets (Fouad et al., 2001; Girgis et al., 2007; Cao et al., 2010; Ueno et al., 2012; Tandon et al., 2013). This approach, like behavioral testing of motor function, remains subject to ambiguity regarding the underlying circuitry that mediates the behavioral response. Elegant examples exist in which selective stimulation of axon tracts has been combined with intracellular recordings of postsynaptic activity, with the latency to response used to distinguish direct from indirect connections (Hunanyan et al., 2013). However, this approach is technically demanding and is limited by the difficulty in selectively stimulating axonal populations of interest.

Recent advances in optogenetic techniques provide a potential solution to the problem of specifically monitoring the functional connectivity of newly grown axons. Channelrhodopsin (ChR2), a light-sensitive cation channel, can be specifically expressed in subsets of neurons, allowing action potentials to be selectively generated in ChR2-expressing cells by exposure to light of an appropriate wavelength (Lüscher et al., 2015). In addition, ChR2 protein is effectively trafficked to axon terminals, in which light exposure can stimulate vesicular release (Petreanu et al., 2009) and the generation of action potentials in postsynaptic partners (Stuber et al., 2011; Tye et al., 2011). Using Sox11induced growth of corticospinal tract (CST) axons as a model system, we have developed an optogenetic strategy to monitor the emergence of functional synaptic connectivity. Vesicular release was stimulated specifically in newly grown, ChR2-expressing CST axons while postsynaptic activity was monitored with singleunit extracellular recording, demonstrating the ability of these axons to drive postsynaptic activity. These findings illustrate a flexible and technically amenable means to monitor synaptic function in the context of stimulated axon growth. The data also indicate that, in the case of Sox11-induced axon growth, suboptimal behavioral recovery is not the result of failed synaptogenesis, directing future attention toward the hypothesis that inappropriate cellular targeting limits behavioral gains.

\section{Materials and Methods}

\section{Animals and behavioral testing}

All experiments were conducted following protocols approved by the Marquette University Animal Care and Use Committee, in accordance with the National Institutes of Health Guide for the Care and Use of Laboratory Animals. Female C57BL/6 mice were housed in a temperature- and humidity-controlled vivarium with food and water available ad libitum. Mice were maintained on a $12 \mathrm{~h}$ light/dark cycle, and all procedures were conducted during the light phase of the cycle (beginning at 7:00 A.M.). Pyramidotomies were performed as described previously (Wang et al., 2015). Briefly, animals were anesthetized, and a craniotomy of the occip- ital bone was performed using laminectomy forceps to expose the underlying pyramidal tract. Then a microfeather scalpel was used to puncture the dura and lesion the entire left pyramidal tract. One week later, animals were placed in a stereotaxic frame (Stoelting Mouse Adaptor), a craniotomy was performed, and $0.3 \mu$ l viral particles $\left(1 \times 10^{13} / \mathrm{ml}\right)$ were delivered by Hamilton syringe and Stoelting QSI infusion pump $(0.03$ $\mu \mathrm{l} / \mathrm{min}$ ) to five sites located $1.2-1.5 \mathrm{~mm}$ lateral (left) and $0.2-0.7$ anterior from bregma and $0.55 \mathrm{~mm}$ below the surface of the brain. The needle was then withdrawn, and the skin was closed with staples. AAV9-CaMKIIChR2(H134R)-EYFP was obtained from the University of North Carolina Viral Vector Core. AAV8-EBFP-2A-mCherry and AAV8Sox11-2A-mCherry, modified with H2B fusion protein to render the mCherry localized to nuclei (Kanda et al., 1998), were from the University of Miami viral vector core as described previously (Wang et al., 2015). Mice were tested weekly on a horizontal ladder $(30 \mathrm{~cm}$ long, $1 \mathrm{~cm}$ rung spacing) task before and after pyramidotomy and adeno-associated virus (AAV) injection in the motor cortex (Wang et al. 2015). Animals were pretrained in two four-run sessions on the horizontal ladder, and then tested after treatment in four-crossing sessions with percentage error quantified on the last three runs. On the final week of testing, rung spacing was increased by removing an alternate rung for every two rungs. Animals were recorded using a digital camera, and the number of foot slips, normalized to total steps, was scored by a blinded observer. Animals were tested for skilled forelimb reaching behavior using the mouse staircase task (Lafayette Instruments). Animals were food restricted to maintain $80 \%$ of their body weight and trained daily on the staircase for 30 $\mathrm{min} / \mathrm{d}$ with two high-fat diet $20 \mathrm{mg}$ pellets (BioServ) placed on each of eight steps. After cortical injection and pyramidotomy, animals were tested twice weekly, and the numbers of pellets retrieved and displaced were recorded (Starkey et al., 2005).

\section{Electrophysiological recording procedures}

Animals were anesthetized using a mixture of urethane $(3.33 \mathrm{~g} / \mu \mathrm{kg}$ body weight) and xylazine $(15 \mathrm{mg} / \mathrm{kg})$. Animals were then placed in a custom spinal stabilization device, and the spinal cord between C4 and C5 was exposed. Heads were immobilized in ear bars (Stoelting), and the skin above the skull was cut to expose the craniotomy region in which the virus was injected. In control experiments involving spinal transections to isolate right and left spinal cord, a tungsten microelectrode $(800 \mu \mathrm{m}$; FHC) was inserted at the C4 midline, or $100 \mu \mathrm{m}$ lateral to the midline, lowered until contact was made with ventral bone, and then moved to rostral C6 while maintaining bone contact, thus creating a complete lesion in the sagittal plane.

Optical stimulation. Blue (473 nm) DPSS Laser (Shanghai Laser and Optics Century) light was directed via collimator into a $200-\mu \mathrm{m}$ diameter optical fiber (Thorlabs) tipped with a ferrule encasing a 2 -inchlong polished fiber $(200 \mu \mathrm{m}$ diameter $)$ and held in place with a stereotaxic instrument (David Kopf Instruments). Output power (5-20 $\mathrm{mW}$ ) from the tip of the fiber was measured using an optical power meter (PM130D; Thorlabs) and was adjusted to maximize the effectiveness of stimulation. Pulses were generated using transistor-transistor logic modulation (Arbitrary Waveform Generator, $20 \mathrm{MHz}$; Agilent 33220A). The optical fiber was positioned at the surface of the brain or spinal cord, and the light was directed to the location of the recording electrode. Six pulse trains were generated, each consisting of three pulses, $1 \mathrm{~s}$ each with $1 \mathrm{~s}$ intervals. Cells were stimulated for a total period of six trains with $15 \mathrm{~s}$ gap between each train.

Single-unit data acquisition. Single-unit extracellular recordings were acquired using a 32-channel silicon electrode (NeuroNexus Technologies), designed for extracellular somatic recordings. Signals were relayed via a smart-link head stage and then amplified, digitized, and stored in an integrated unit (Smartbox; NeuroNexus Technologies). The signals were sampled at $30 \mathrm{kS} / \mathrm{s}$. Digital-to-analog converter high-pass filter settings was set to $250 \mathrm{~Hz}$ and the Notch filter to $60 \mathrm{~Hz}$. The electrode was stereotaxically lowered into the motor cortex or ventral horn of the spinal cord. Baseline activity recordings of each unit were conducted for $30 \mathrm{~s}$ before light-evoked activity was measured. Data acquired from unit recordings were appended with the timestamp of laser stimulation using MATLAB (MathWorks) and were exported to Spike2 version 8.00 
(Cambridge Electronics Design). Discrimination of individual waveforms corresponding to the activity of an individual neuron was accomplished with principal component analysis using Offline Sorter (Plexon). In all electrophysiology experiments, only biphasic waveforms indicative of somatic recordings were observed (Terzuolo and Araki, 1961; Lemon, 1984; Barry, 2015).

Categorization of electrophysiological response to optical stimulation. Firing rate change in response to laser stimulation was characterized by generating peri-event raster histograms (100 ms bins) surrounding each stimulation event using Neuroexplorer version 4.126 (Nex Technologies). Each histogram was divided into 18 baseline epochs ( $1 \mathrm{~s}$ before each laser onset) and 18 matching stimulation epochs time locked to laser duration ( $1 \mathrm{~s})$. For each unit, a paired $t$ test $(\alpha=0.05)$ was conducted to compare baseline and stimulation firing rate, and units that exhibited mean firing rate change $>2$ spikes/s and a significant difference $(p<$ $0.0001)$ in this analysis were classified as exhibiting laser-evoked activity. $\chi^{2}$ tests were used to compare the proportion of light-responsive cells across treatments.

\section{Histology}

Immediately after electrophysiological recordings, animals were killed with $\mathrm{CO}_{2}$. Brain and spinal cord were removed and fixed in $4 \%$ paraformaldehyde overnight at $4^{\circ} \mathrm{C}$. The cortex, medulla, and spinal cord from 2 $\mathrm{mm}$ rostral to $4 \mathrm{~mm}$ caudal from the injury site were embedded in $12 \%$ gelatin (Sigma), and $100 \mu \mathrm{m}$ free-floating sections were cut on a Leica VT100S Vibratome. Immunohistochemistry for PKC $\gamma$ was performed on free-floating sections using 20\% normal goat serum/PBS block, rabbit anti-PKC $\gamma$ antibody (1:500; Santa Cruz Biotechnology), and goat antirabbit Alexa Fluor 647 (1:500; Invitrogen). Sections were then mounted onto glass slides, and images were obtained using a Nikon Eclipse TI or Zeiss LSM 5 Pascal confocal microscope. PKC $\gamma$ intensity was quantified in injured and intact CST by NIS Elements software; exclusion criteria for animals was $<80 \%$ reduction in average intensity on the injured side. The total number of transduced $\left(\mathrm{EYFP}^{+}\right)$CST fibers was quantified using transverse sections of medulla by sampling three regions $(4000$ $\mu \mathrm{m}^{2}$ ) of the pyramid at $60 \times$ magnification and then extrapolating based on total cross-sectional area (Lee et al., 2010; Blackmore et al., 2012; Wang et al., 2015). EYFP ${ }^{+}$profiles that intersected virtual lines at set distances from the spinal midline were quantified by a blind observer on an Olympus IX81 microscope and then normalized to total axons in transverse medullary sections (Blackmore et al. 2012, Wang et al. 2015). $\mathrm{EYFP} / \mathrm{mCherry} \mathrm{colocalization} \mathrm{was} \mathrm{assessed} \mathrm{in} \mathrm{cortical} \mathrm{sections} \mathrm{by} \mathrm{confo-}$ cal microscopy using a Zeiss axioplane 2 microscope with SPOT digital photomicroscopy capabilities, a Pulnix CCD camera, and a Mac-based (G5) image analysis system.

\section{Results}

\section{Viral expression of ChR2 allows optogenetic activation of} cortical neurons

Validation and time course of optogenetic stimulation of cortical neurons

To enable controllable activation of cortical neurons in adult mice, we injected viral particles carrying EYFP-tagged ChR2 under the control of a CaMKII promoter [rAAV9/CaMKIIChR2(H134R)-EYFP] to regions of cortex that innervate the cervical spinal cord (Bernstein and Boyden, 2011). In an initial time course experiment, weekly electrophysiology and microscopy assessed the appearance and long-term stability of ChR2 expression and light-evoked activity. First, the sensorimotor cortex of urethane-anesthetized mice was exposed to $473 \mathrm{~nm}$ blue DPSS laser while neuronal activity was recorded in the same region (Fig. 1A). Unlike the spinal cord (below), cortical units were silent in these anesthetic conditions before stimulation. One week after injection, light stimulation caused the appearance of time-locked activity of cortical neurons at $9 \%$ of recording positions along the electrode, and this value increased to $28 \%$ by the 4 week time point (Fig. 1B,C). Responsive units were distributed across cortical depths but were most frequent in the deeper cortical layers that were targeted for injection (Fig. 1E). Consistent with the electrophysiology, EYFP fluorescence was dimly visible in cortical sections 1 week after injection and was readily detectable by 4 weeks (Fig. 1D). Interestingly, at later time points, an inverse relationship developed between laser power and neuronal firing rates. When using $5 \mathrm{~mW}$ laser power, evoked rates of firing showed a trend toward reduction at later time points: $18.2 \pm 4.4$ spikes/s at 2 weeks, $13.4 \pm 2.2$ spikes/s at 4 weeks, and $9.4 \pm 1.8$ spikes/s at 8 weeks. However, in the same 8 week recording sessions, when laser power was reduced below $1 \mathrm{~mW}$, the evoked firing rates were significantly increased and returned to rates similar to the earlier time points $(16.6 \pm 2.0$ spikes $/ s, p<0.05$, paired $t$ test compared with $5 \mathrm{~mW}$ power). One possibility for this progressive change is that increasing amounts of ChR2 protein led to transition from excitation to inhibition of the cells at higher laser power (Liske et al., 2013). Nevertheless, these data confirm a rapid and stable expression of virally delivered $\mathrm{ChR} 2$ protein and the expected excitatory responses to light in cortical neurons.

Cortical activity is expected to drive postsynaptic responses by spinal neurons, which can potentially arise from both direct communication by CST axons or polysynaptic relay circuits though subcortical nuclei, including the red nucleus, reticular neurons, or propriospinal neurons (Alstermark et al., 2004; Nielsen et al., 2007; Harrison et al., 2012). To confirm that optogenetic stimulation of cortical neurons evokes neural activity in the spinal cord, the cortex was exposed to intervals of $473 \mathrm{~nm}$ light, and the recording electrode was placed in gray matter of the cervical spinal cord (Fig. 2A). Light stimulation of cortical neurons elicited clear increases in the rate of firing by spinal neurons, and the responses persisted for the 4 week duration of the experiment (Fig. 2B, C). These data show that optogenetic stimulation of ChR2-expressing cortical neurons, acting through direct and/or relay connections, results in postsynaptic responses by spinal neurons.

\section{Emergence of terminally evoked spinal activity}

Optogenetic stimulation of axon terminals has emerged as an approach to assess direct functional connectivity in other CNS axon tracts. To apply this strategy to cortical-spinal communication, we performed unilateral (left) injection of AAV9ChR2(H134R)-EYFP to the cortex and then monitored the cervical spinal cord for the expression of ChR2 in CST axons, the only direct cortical-spinal projection. EYFP fluorescence in the right CST (a crossed tract) was first detected 2 weeks after viral injection, 1 full week after detection in cortical cell bodies, likely reflecting a lag in the axonal transport of the ChR2 protein (Fig. 3C). EYFP fluorescence increased in intensity by 4 weeks, and by 8 weeks individual collateral sprouts were clearly visible in the gray matter of the spinal cord (Fig. 3C). Thus, EYFP-ChR2 is expressed in CST terminals at increasing levels during 8 weeks after viral injection to the cortex.

To determine whether direct activation of ChR2 in CST axons is sufficient to elicit postsynaptic responses in spinal neurons, we exposed the cervical spinal cord to $473 \mathrm{~nm}$ light while monitoring spike activity with a multichannel silicon electrode inserted in recording sites between C3 and C5. Electrodes were placed 200 and $500 \mu \mathrm{m}$ lateral to the midline, and the 32 recording sites along the electrode were distributed 250-1750 $\mu \mathrm{m}$ below the dorsal surface (Fig. $3 A$ ). One week after viral injection, we observed spontaneous activity in 42 distinct units in spinal cord tissue, none of which significantly altered firing rate during light exposure $(p>0.05)$. These negative data are consistent with the lack of detectable ChR2 protein in CST terminals at this time 

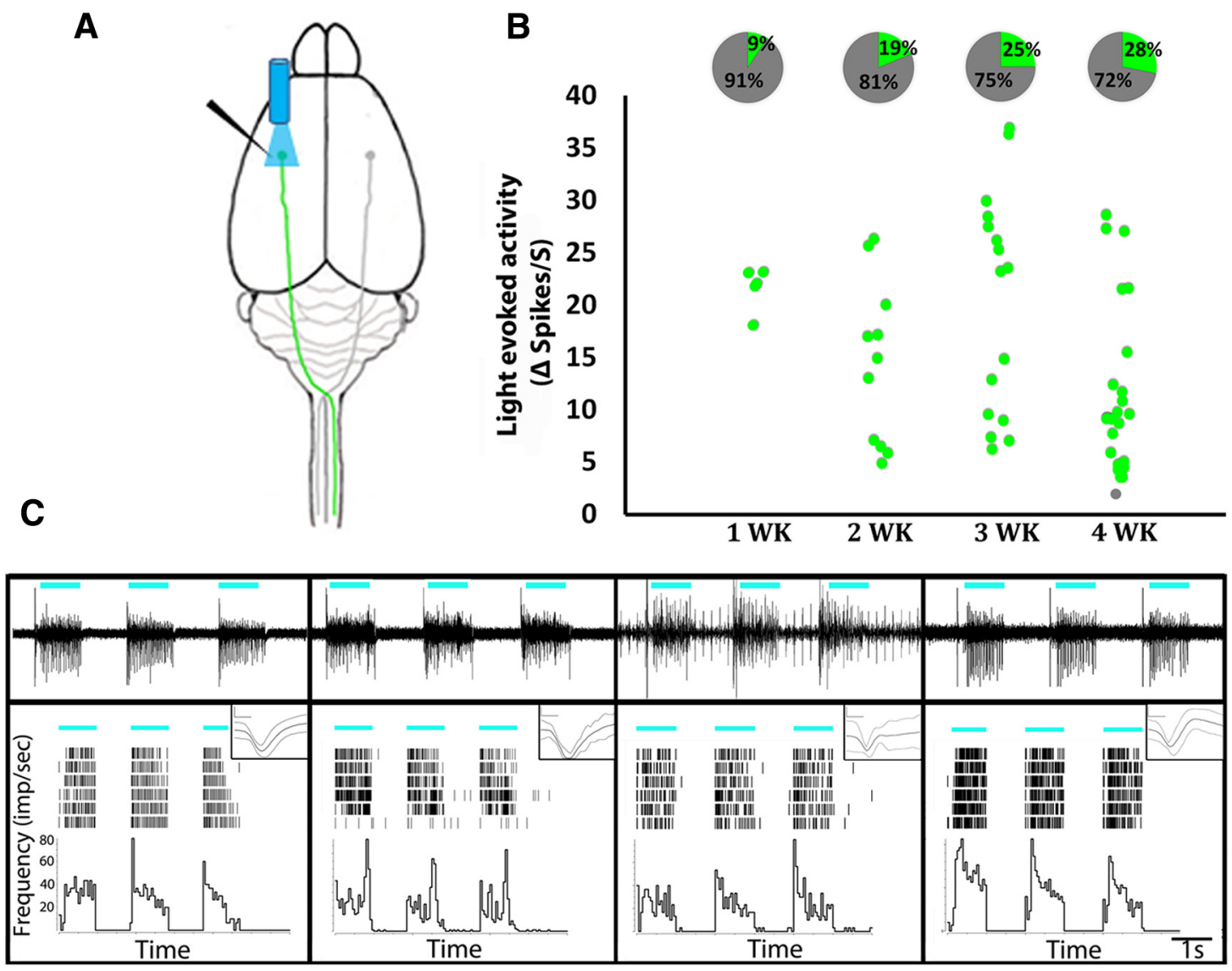

D

E
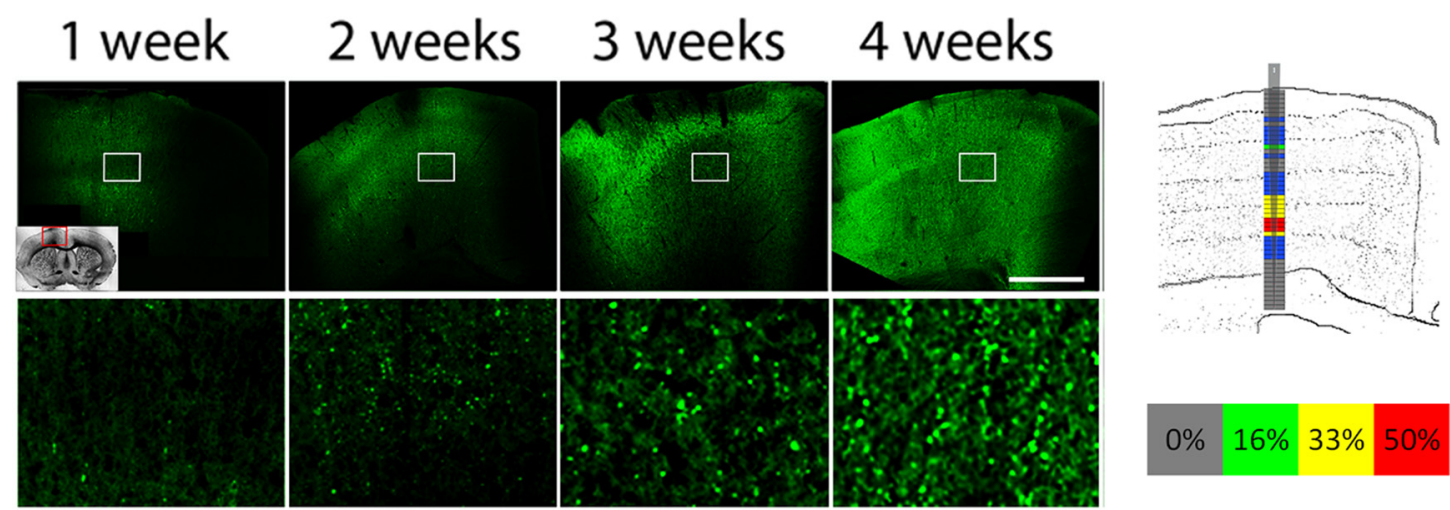

Figure 1. Time course of cortical expression and function of virally expressed ChR2. A, AAV-ChR2(H134R)-EYFP was injected in the left cortex. One to 4 weeks after injection, the cortex was exposed to $473 \mathrm{~nm}$ light while a 32-channel recording electrode monitored cortical activity. $\boldsymbol{B}$, Firing rates were monitored during light stimulation and paired unstimulated periods. Each dot represents an individual cortical unit; green indicates a significant increase in firing rate during light stimulation (paired $t$ test, $p$ values $<0.005,>2$ spikes $/ s$ change). Pie charts indicate percentage of recording channels in which significant light-evoked activity was recorded. The proportion of responsive units was significantly greater at 4 weeks compared with 1 week after injection $\left(\chi^{2}\right.$ test; $p<0.01$ ). C, Examples of unit activity (top) and corresponding peri-event rasters and histograms (bottom) of individual neuronal responses. Activity was reliably evoked by light stimulation (blue lines). $\boldsymbol{D}$, The cortex was imaged by fluorescent confocal microscopy. EYFP-ChR2 (green) was dimly detected 1 week after injection and plainly visible by 4 weeks. $\boldsymbol{E}$, Heat map indicates the percentage of recordings in which light-evoked increases in firing rate were observed at each location along the recording electrode. $n=3$ animals per time point. Scale bar, $0.5 \mathrm{~mm}$.

point. At 2 weeks after injection, 12 of 43 spontaneously active units $(28 \%)$ increased firing rate during periods of light stimulation ( $p<0.0001$, paired $t$ test, $>2$ spikes/s change). In all spinal experiments, only biphasic waveforms indicative of somatic recordings were observed, consistent with the expectation that this electrode configuration is insensitive to small axonal events (Terzuolo and Araki, 1961; Lemon, 1984). At 3, 4, and 8 weeks after injection, between 50 and $55 \%$ of spontaneously active units increased firing rate during periods of light stimulation, indicating a plateau of efficacy that is reached by 3 weeks after injection (Fig. $3 B, D)$. As expected from the crossed anatomy of the CST, lightevoked changes in postsynaptic responses were detected only on the right side of the spinal cord, contralateral to the unilateral site of injection in left cortex (Fig. $3 E, F$ ). Overall, these data confirm the efficacy of terminal optical stimulation in CST axons and indicate the ability of direct CST input to the spinal cord, as opposed to relay circuits, to modulate the activity of spinal neurons. 
A

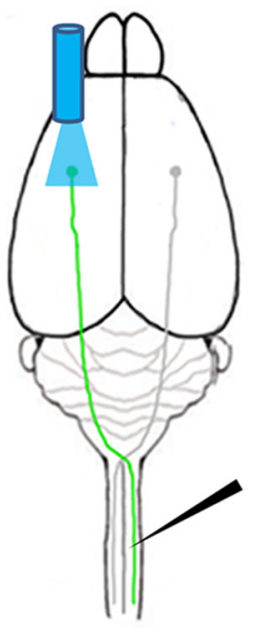

B

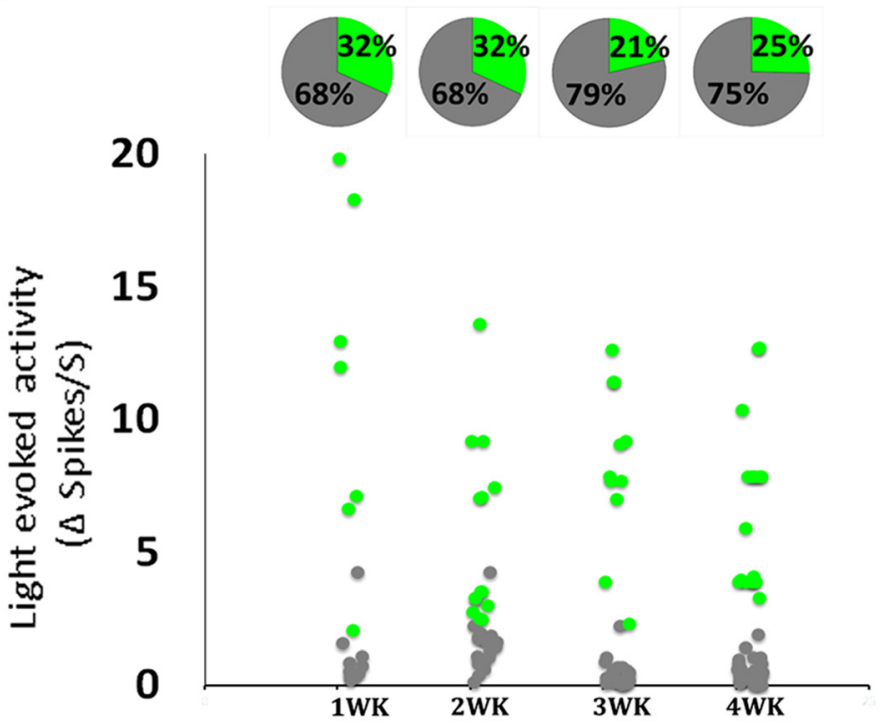

C

\section{1 week 2 weeks}

\section{3 weeks}

4 weeks

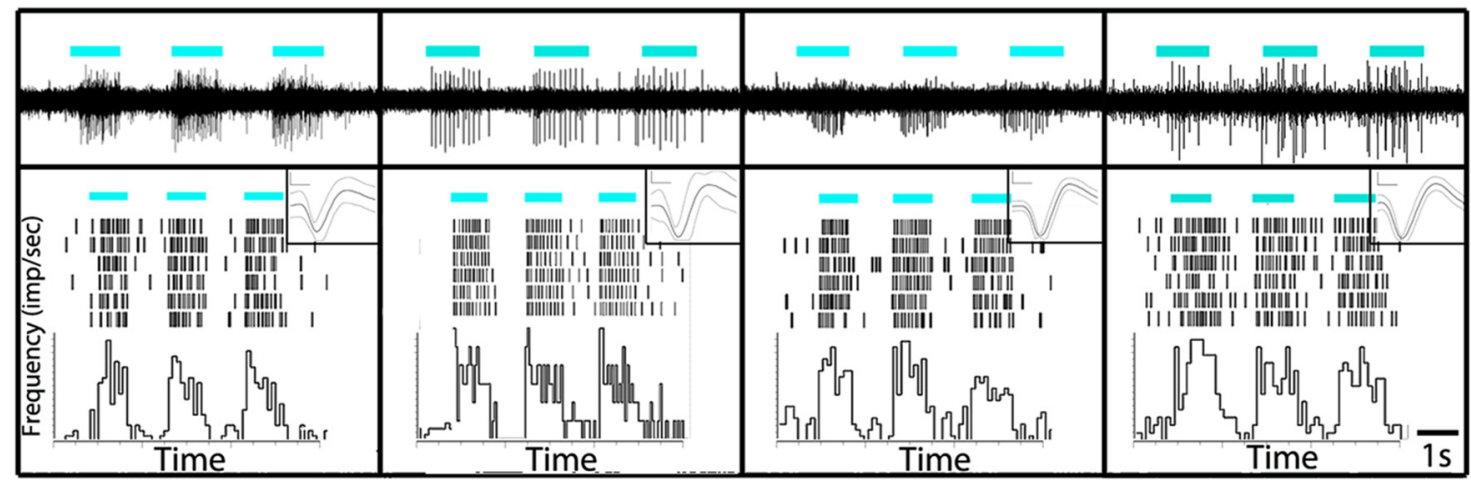

Figure 2. Optically driven cortical activity evokes postsynaptic responses in the spinal cord. A, AAV-ChR2(H134R)-EYFP was injected in the left cortex, and 1 and 4 weeks later the cortex was exposed to $473 \mathrm{~nm}$ light while a recording electrode was inserted into the right cervical spinal cord. $\boldsymbol{B}$, Firing rates were monitored during light stimulation and paired unstimulated periods. Each dot represents an individual spinal unit; green indicates a significant increase in firing rate during light stimulation (paired $t$ test, $p$ values $<0.005,>2$ spikes/s change). Pie charts show the percentage of cells that significantly increased firing rate during light stimulation. More than $25 \%$ of spinal units were light responsive at all time points, with no significant difference across time ( $p>0.05, \chi^{2}$ test). C, Examples of unit activity (top) and corresponding peri-event rasters and histograms (bottom) of individual neuronal responses. Activity was reliably evoked by light stimulation (blue lines). $n=3$ animals per time point.

\section{Optogenetic assessment of functional connectivity by newly sprouted CST axons}

We next used terminal optogenetic stimulation to monitor changes in direct CST input to the spinal cord after injury. Unilateral pyramidotomy was performed to deprive the left spinal cord of CST input (confirmed by PKC $\gamma$ immunostaining; Starkey et al., 2005; Wang et al., 2015), and unilateral AAV injections supplied the intact (right) CST axons with ChR2. In these animals, AAV-ChR2 was mixed with control AAV-EBFP to enable comparison with a second treatment group (AAV-ChR2/AAVSox11 mixture; described below). Previous work has established that, in the absence of therapeutic intervention, intact CST axons display a limited ability to sprout across the spinal midline and compensate for lost CST input (Lee et al., 2014; Du et al., 2015; Wang et al., 2015). As expected, animals treated with AAV-EBFP control showed minimal midline crossing of CST axons in the cervical spinal cord (Fig. $4 I, K$ ). To test the degree to which spontaneous plasticity resulted in restoration of direct cortex-spinal communication to the denervated spinal cord, the cervical spinal cord was unilaterally exposed to $473 \mathrm{~nm}$ light while postsynaptic excitatory responses were monitored with a multichannel electrode (Fig. $4 I, K$ ). Data were collected at 4 and 8 weeks after injury, at C3 and C5, with the electrode positioned 200 or $500 \mu \mathrm{m}$ from the midline on both the intact (right) and denervated (left) side of the spinal cord. In the right (intact) spinal cord at 4 weeks after injury, 40\% (37 of 92) of units at C5 and 49\% (45 of 92) of units at C3 significantly increased their spontaneous firing rate during light stimulation. In contrast, on the left (denervated) side of the cord, $0 \%$ ( 0 of 60$)$ and 2\% (2 of 85) of units at C5 and C3 increased firing during light stimulation. Results at the 8 week time point were similar, with $27 \%$ (29 of 109) and 45\% (57 of 127) of units showing light-enhanced activity in the right $\mathrm{C} 3$ and $\mathrm{C} 5$ spinal cord, respectively, compared with $2 \%$ ( 2 of 81 ) and $1 \%$ (1 of 95) in mirrored positions on the left (Fig. $4 I, K$ ). These data confirm that, as predicted from the minimal degree of spontaneous growth of CST fibers into denervated spinal cord, endogenous repair mechanisms normally create minimal direct functional connectivity between the intact CST and contralateral spinal neurons.

One way to enhance sprouting across the midline by CST neurons is to force the expression of Sox 11, a pro-regenerative 
A

B

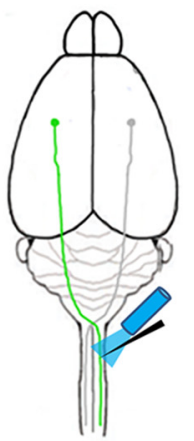

C

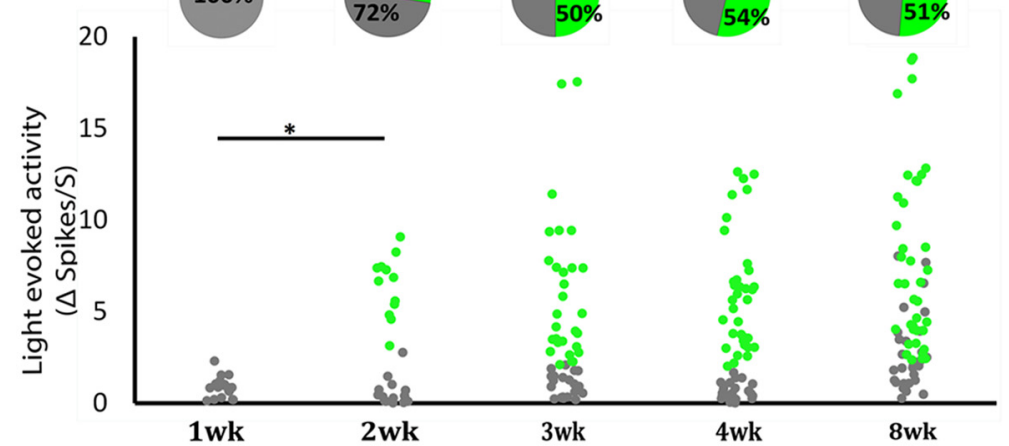

\section{1 week 2 weeks 3 weeks 4 weeks 8 weeks}
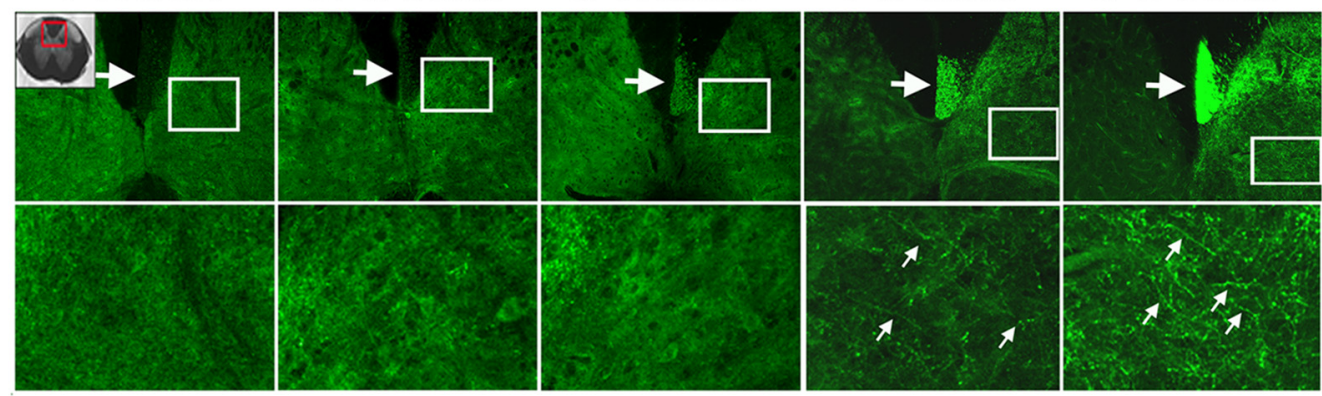

D
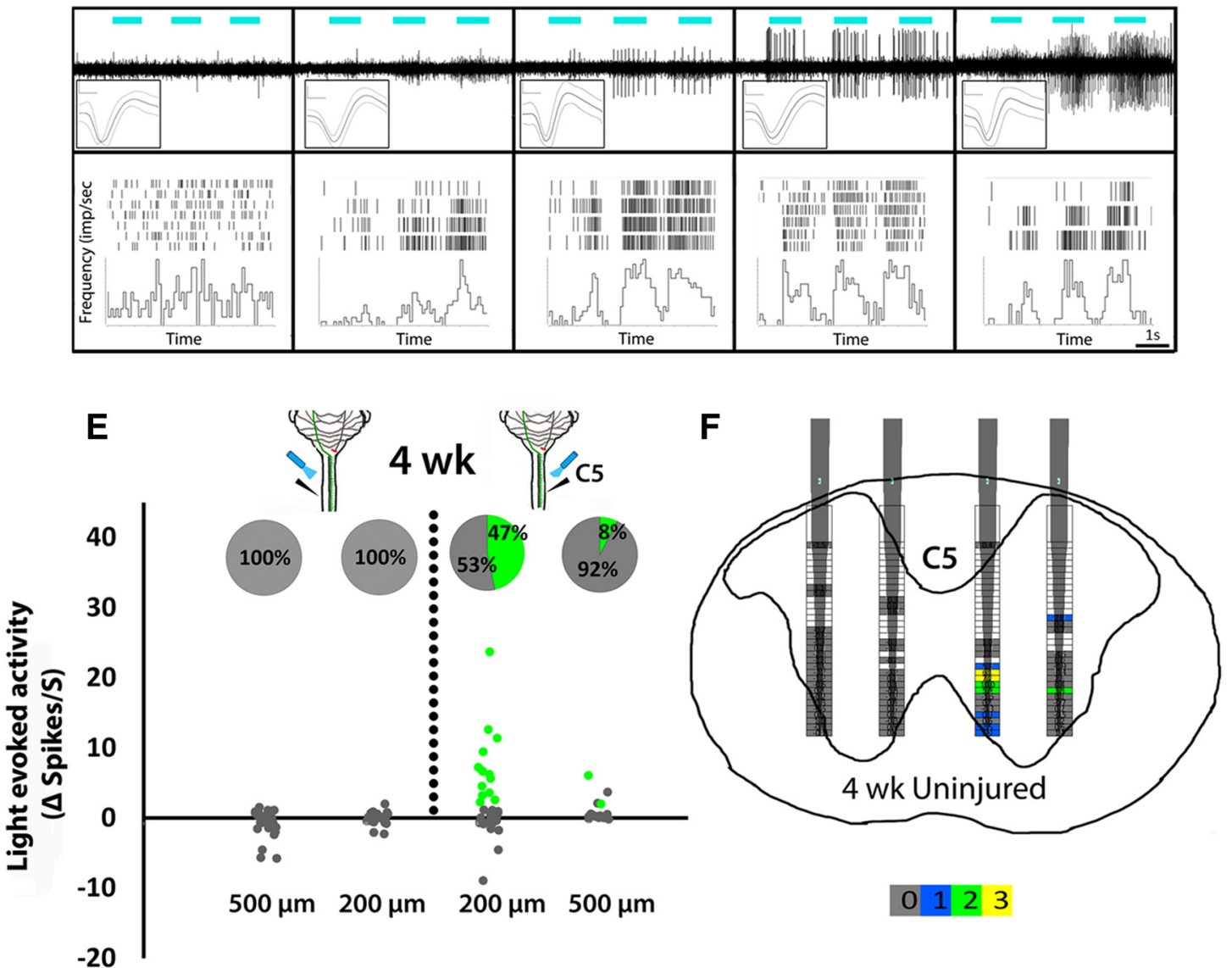

Figure 3. Terminal stimulation of ChR2 in CST axons drives postsynaptic activity in spinal cord neurons. A, Optical simulation was applied to the right cervical spinal cord after left cortical injection of AAV-ChR2(H134R)-EYFP. B, Each dot represents a spontaneously active spinal unit. Pie charts show the percentage of cells that significantly increased firing rate during light stimulation. Starting 2 weeks after injection, some spinal units (green) showed significant increases in firing rate during light stimulation ( $p$ values $<0.0001,>2$ spikes/s change, paired (Figure legend continues.) 
transcription factor that is normally expressed developmentally during periods of axon growth and then downregulated (Wang et al., 2015). To determine the degree to which direct communication by the new CST input is capable of modulating spinal activity, we injected a second group of animals in the pyramidotomy experiment with mixed AAV-ChR2-EYFP and AAV-Sox11$2 \mathrm{~A}-\mathrm{H} 2 \mathrm{~B}-\mathrm{mCherry}$. Inspection of the cortex 8 weeks after transduction showed that $86.2 \%$ of ChR2-EYFP ${ }^{+}$neurons coexpressed mCherry (localized to the nucleus by the H2B fusion), confirming efficient cotransduction from the two viruses (Fig. $4 M, N)$. PKC $\gamma$ immunohistochemistry confirmed lesion completeness, and visualization of $\mathrm{EYFP}^{+} \mathrm{CST}_{\text {axons confirmed ele- }}$ vated midline crossing of CST axons in the Sox 11-treated animals (Fig. $4 C, D, G, H$ ). Similar to other instances of stimulated axon growth into spinal tissue, immunohistochemistry revealed examples of putative synapses in which Sox11-stimulated sprouts colocalize with synaptic proteins (Fig. $4 G$, inset). However, it is unclear whether these putative synapses are indeed functional. Therefore, we performed terminal optogenetic stimulation paired with extracellular single-unit recordings, as above (Fig. $4 J, L)$. Similar to EBFP controls, spinal units in the right (intact) spinal cord showed robust responses to optical stimulation of CST terminals, with 31.9\% (39 of 188) and 45.6\% (108 of 294) units showing significant elevations in activity at 4 and 8 weeks after injury, respectively. In contrast to EBFP controls, many units in the left (previously denervated) cord also showed increases in activity when light was directed to the left side of the cord: $20.7 \%$ (69 of 216, 4 weeks) and $36.7 \%$ (140 of 307, 8 weeks) of units significantly increased firing rates. Importantly, the total number of CST axons that expressed ChR2EYFP, assessed in cross-section at the level of the medullary pyramids (Lee et al., 2010; Blackmore et al., 2012; Wang et al., 2015), was similar between treatment groups and across time (mean \pm SEM; EBFP 4 weeks, $4087 \pm 738$; EBFP 8 weeks, $4242 \pm$ 406; Sox11 4 weeks, $4120 \pm 320$; Sox11 8 weeks, $3854 \pm 873 ; p>0.05$, two-way ANOVA). These data show that specific stimulation of Sox 11-treated CST axons is sufficient to modulate the activity of spinal neurons, indicating newly established, direct functional connectivity between CST axons and spinal neurons in the left spinal cord.

We considered and excluded alternative explanations in a series of control experiments using Sox11-treated animals. Importantly, all animals in the control experiments had confirmed right-to-left sprouting of CST axons, and we confirmed that 56\% of left spinal units responded to light directed to the left spinal cord (direct terminal stimulation of sprouted axons; Fig. 5A). One possibility is that spinal activity in the left cord was secondary to optical scattering that erroneously stimulated intact CST

\section{$\leftarrow$}

(Figure legend continued.) $t$ test); the proportion of light-responsive cells increased between 1 and 2 weeks after injection ( $p<0.01, \chi^{2}$ test). C, EYFP-ChR2 (green) was dimly detected 3 weeks after injection, and by 4 to 8 weeks, collateral sprouts were visible in spinal gray matter (arrows). D, Examples of unit activity (top) and corresponding peri-event rasters and histograms (bottom) of individual neuronal responses aligned to light stimulation (blue lines). $\boldsymbol{E}, \boldsymbol{F}$, At the 4 week time point, the spatial distribution of light-evoked activity was determined by placing multiunit electrodes 200 or $500 \mu \mathrm{m}$ bilaterally from the spinal midline. Significant increases in firing rate (green dots, $\boldsymbol{E}$ ) were observed only in the right spinal tissue, contralateral to the site of cortical injection. Pie charts show the percentage of cells that significantly increased firing rate during light stimulation. $\boldsymbol{F}$, The heat map indicates the location of spontaneously active spinal units (open boxes indicate no spontaneous activity), and the percentage of animals in which light-evoked changes in activity were observed at each recording position. $n=3$ animals per time point. Scale bar, $0.5 \mathrm{~mm}$. axons on the right side of the spinal cord. If so, CST-evoked activity in the right spinal cord could potentially be activating the left spinal cord indirectly via commissural neurons. We excluded this possibility in two ways. First, we recorded activity in the right cord while optically stimulating the left, and found that only $2 \%$ of right spinal units were light responsive in this configuration, indicating successful localization of light to the left spinal cord (Fig. 5A). Second, light was directed to the right spinal cord while recording from the left, to test the degree to which deliberate stimulation of the right spinal cord led to relay stimulation of the left. Only $1 \%$ of left spinal neurons were light responsive in this configuration (Fig. $5 A$ ), indicating a minimal potential for erroneous cross-midline stimulation. Finally, we used acute sagittal transections of C4-C5 spinal cord to separate collateral CST sprouts from contralateral spinal cord and from their parent axons and cell bodies. Lesion placement and completeness were confirmed in transverse spinal sections (Fig. 5C,D). In both EBFP-treated axons, which displayed normal collateralization into right spinal cord, and in Sox11-stimulated axons that sprouted into left spinal cord, robust postsynaptic responses to terminal stimulation persisted after sagittal transections had isolated the terminals from the dorsal CST and from contralateral gray matter (Fig. $5 E, F$ ). These data confirm the sufficiency of isolated CST terminals, in the absence of input from contralateral spinal cord, to evoke local postsynaptic spinal responses.

We also considered the possibility that terminal optical stimulation could generate antidromic action potentials in CST axons, which could contribute to spinal activation through upstream relays in the spinal cord, brainstem, or midbrain. Because optical antidromic activation is strongly affected by the distance to the cell body (Tye et al., 2011) and requires very high light intensity ( $>30 \mathrm{~mW}$; Ciocchi et al., 2015), we did not anticipate that $<5 \mathrm{~mW}$ stimulation of CST axons in cervical spinal cord would cause antidromic action potentials. Nevertheless, we addressed the possibility in two ways. First, we directly assessed antidromic activation of CST neuronal cell bodies. Cells were first identified in which direct optical stimulation of the cortex led to robust activation, confirming ChR2 expression. Light was then directed to cervical spinal cord. At 92 recording sites across three animals, we found no instances in which firing was evoked by spinal light stimulation (Fig. $6 A, B$ ). These data argue against the prevalence of antidromic stimulation of CST cell bodies. Second, because our previous data established the ability of CST input to drive activity in the right spinal cord, it is notable that optical stimulation of CST sprouts in left spinal cord failed to elicit activity in the right spinal cord (Fig. 5A), as would be expected if antidromic action potentials were generated. In summary, these control experiments discount light scattering, right-to-left relays, or antidromic action potentials as possible mechanisms to explain the increase in firing rate by spinal neurons on optical stimulation of CST axons. Therefore, the newly sprouted, Sox11stimulated CST axons are synaptically competent and, perhaps more importantly, are capable of robustly modulating the activity of spinal neurons through newly formed direct connections.

\section{Spatial distribution of CST-evoked activity in spinal cord}

We have shown previously that enhanced axon growth stimulated by Sox 11 is not associated with behavioral improvements in a pellet retrieval task and can even correlate with slightly worsened performance on the horizontal ladder test of forelimb placement (Wang et al., 2015). Similarly, here we compared control and Sox11-treated animals on a horizontal ladder task and found no significant difference in the rate of foot slips by the affected 

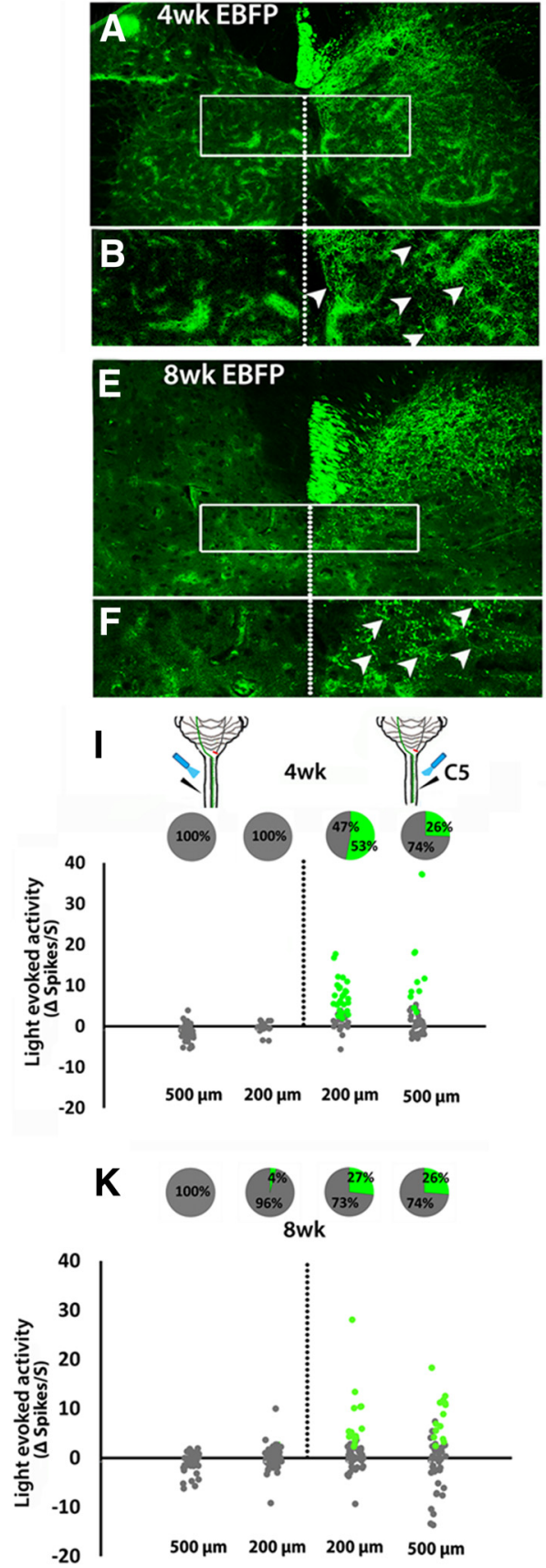
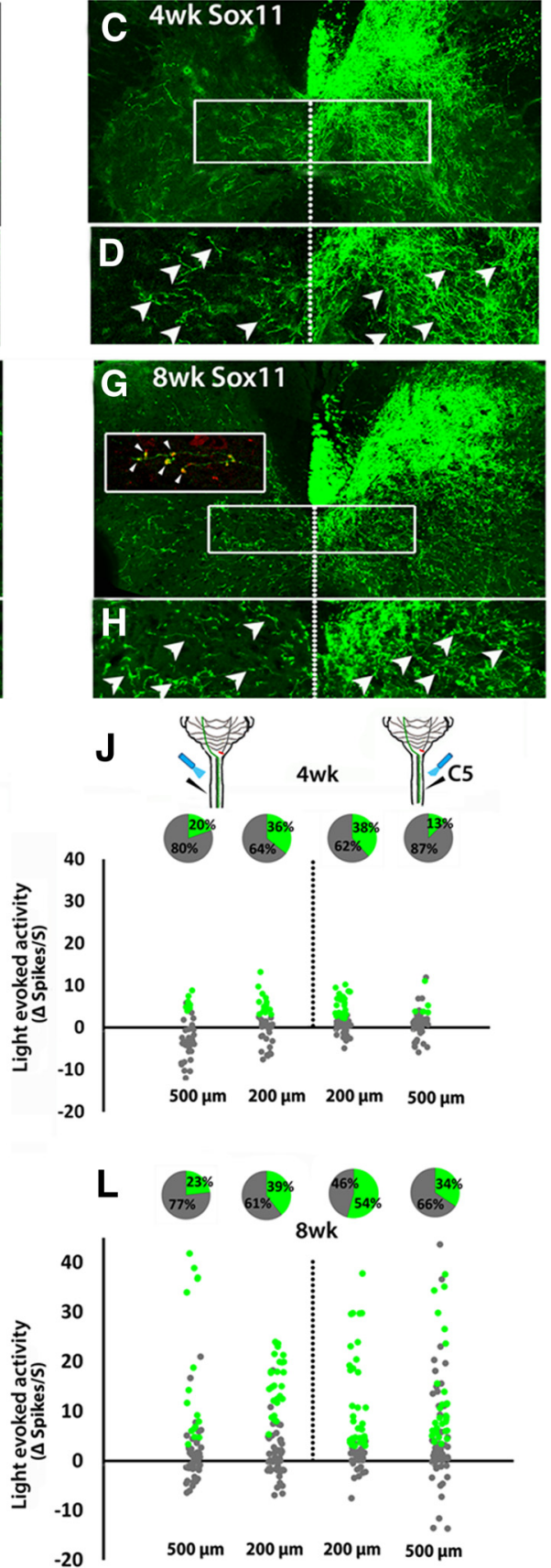
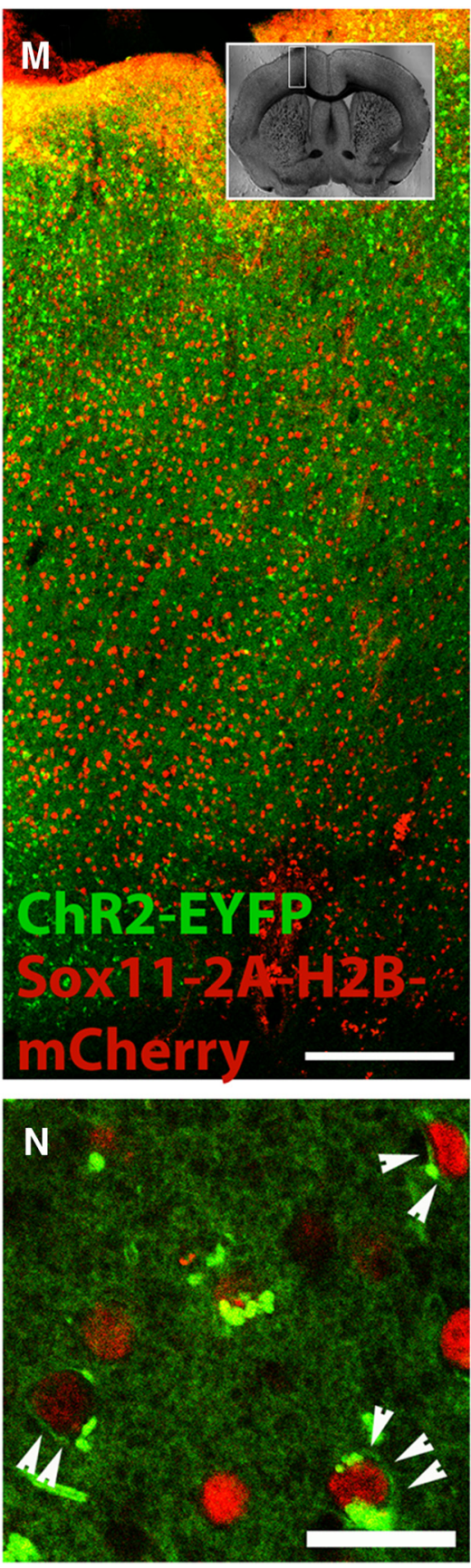

Figure 4. Sox11-transduced CST axons sprout across the spinal midline after pyramidotomy and form functional synapses with spinal neurons. Animals received unilateral pyramidotomy and cortical injection of mixed EBFP/ChR2-EYFP or Sox11/ChR2-EYFP to the uninjured cortex. Four or 8 weeks later, Sox11-treated $(\boldsymbol{C}, \boldsymbol{D}, \boldsymbol{G}, \boldsymbol{H})$ but not EBFP-treated animals $(\boldsymbol{A}, \boldsymbol{B}, \boldsymbol{E}, \boldsymbol{F})$ showed robust midline crossing of CST axons in the cervical spinal cord. Crossed CST axons colocalized with VGluT1 (red, arrowheads, inset in $\mathbf{G}$ ). $I, J$, Optical stimulation of the right and left spinal cord was paired with single-unit extracellular recording. In EBFP control animals, activity was significantly increased by optical stimulation in units located on the right, but not left, spinal cord (green dots, $I$ and $\boldsymbol{K}$ ). Pie charts show the percentage of cells that significantly increased firing rate during light stimulation. Sox11 animals showed significant elevation of firing rates in both right and left spinal cord, indicating activation of spinal units by selective optical stimulation of CST axons that sprouted across the midline. Green indicates $>2$ spikes $/ \mathrm{s}$ increase, $p$ values $<0.0001$, paired $t$ test, $n=4$ animals per treatment. $\boldsymbol{M}, \boldsymbol{N}$, Confocal images of cortex 8 weeks after transduction with ChR2-EYFP (green) and Sox11-2A-H2B-mCherry (red). ChR2-EYFP was diffusely expressed but at high magnification was detectable in cellular membranes (arrowheads, $\boldsymbol{N}$ ), $86.2 \%$ of which coexpressed nuclear localized mCherry. More than 300 cells from three animals were quantified. Scale bars: $M, 250 \mu \mathrm{m} ; \boldsymbol{N}, 20 \mu \mathrm{m}$.

forelimb (mean \pm SEM; EBFP, $27.2 \pm 6.5 \%$; Sox11, $29.1 \pm 7.2 \%$; $p>0.05$, paired $t$ test at 8 weeks after injury). We also used a staircase pellet retrieval task to assess effects of Sox 11 on forelimb function (Baird et al., 2001; Starkey et al., 2005; Balkaya et al., 2013; Fig. 7). Mice retrieved an average \pm SEM of $9.8 \pm 1.6$ pellets before pyramidotomy and cortical injection of ChR2-EYFP with EBFP or Sox 11. Pyramidotomy significantly reduced the number of pellet retrieved by the affected forelimb, and both groups remained similarly impaired (mean \pm SEM; EBFP, $6.6 \pm 1.4$; Sox11, $6.4 \pm 1.4 ; p>0.05$ paired $t$ test, 4 weeks after injury). The number of pellets displaced by reaching attempts was also similar (mean \pm SEM; EBFP, $14.2 \pm 0.7$; Sox 11, $13.3 \pm 0.8 ; p>0.05$, paired $t$ test). Thus, at a range of postinjury time points during which Sox11-stimulated CST axons can drive robust postsynap- 
A
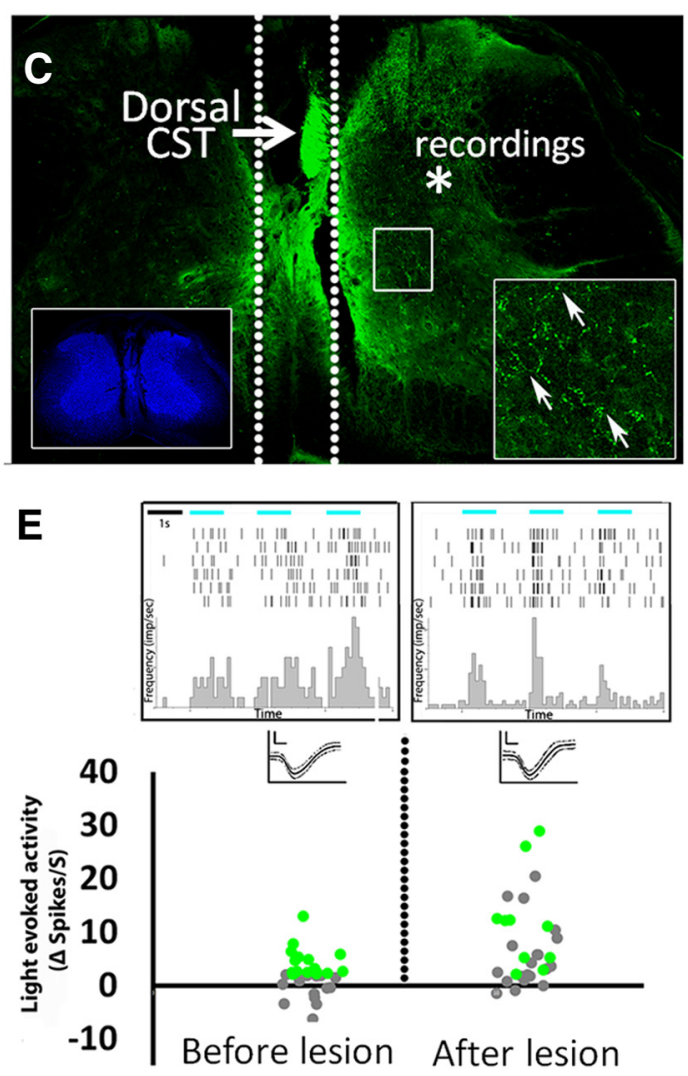

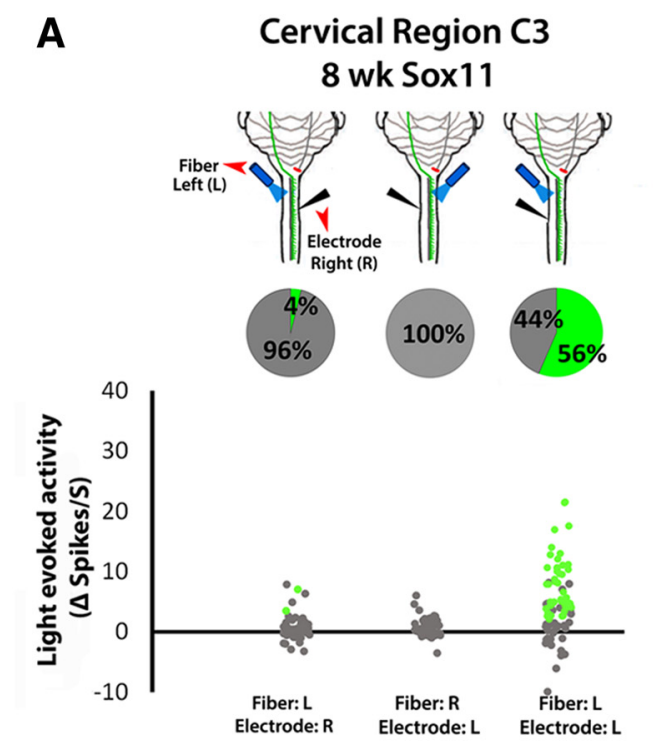

B
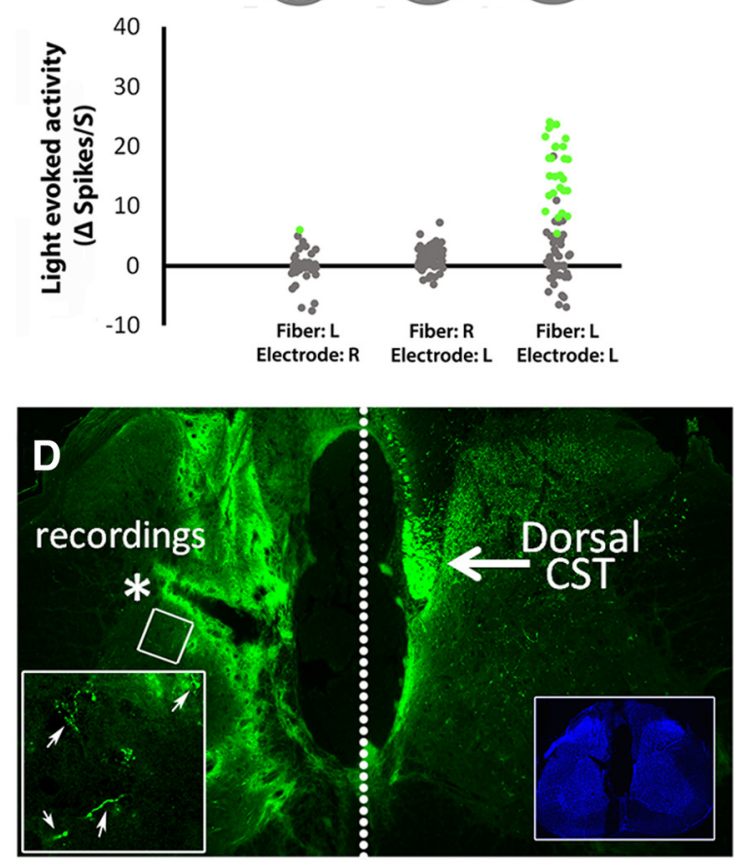

$\mathbf{F}$
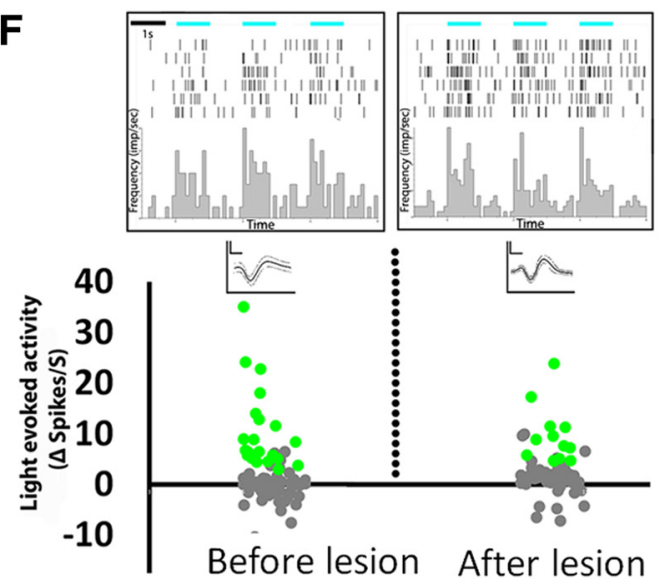

Figure 5. Spinal activity evoked by optical stimulation of cross-midline CST terminals arises from local synaptic connections and not scattered light or antidromic stimulation of commissural relay circuits. $A, B$, In Sox11-treated animals with confirmed crossing of CST axons from right to left spinal cord; recording electrodes and optical fibers delivering $473 \mathrm{~nm}$ light were variably positioned in the right or left spinal cord at $\mathrm{C}(\boldsymbol{A})$ or $\mathrm{C5}(\boldsymbol{B})$. Pie charts show the percentage of cells that significantly increased firing rate during light stimulation. Optical stimulation evoked recorded activity only when both the electrode and the light stimulus were located ipsilaterally, demonstrating local as opposed to relayed spinal responses (dotted lines, $\boldsymbol{C}, \boldsymbol{D})$. C $\boldsymbol{F}$, Animals received cortical injections of AAV-ChR2-EYFP and AAV-EBFP or AAV-Sox11. Eight weeks later, optical stimulation of the cervical spinal was confirmed to evoke significant postsynaptic activity, and then complete sagittal transections were acutely performed to separate the main CST from recording sites (dotted lines, $\boldsymbol{C}, \boldsymbol{D})$. Lesion completeness was confirmed in transverse sections ( $\boldsymbol{C}, \boldsymbol{D}$, insets show nuclear stain). After lesion, optical stimulation of terminals continued to evoke significant increases in firing rates (peri-event raster histogram, $\boldsymbol{E}$ and $\boldsymbol{F}$; green indicates $p<0.0001$, paired $t$ test), confirming the ability of isolated CST terminals to modulate postsynaptic firing in the absence of input from contralateral spinal cord.

tic activity in denervated cervical tissue (Fig. 4J,L), forelimb function is not detectably improved.

These data raise the possibility that the lack of behavioral improvement might be explained by an inappropriate distribution of postsynaptic responses. For example, DRG axons stimulated to regenerate into spinal cord can extend to inappropriate lamina
(Harvey et al., 2009; Smith et al., 2012), motivating the development of tissue-level interventions to limit growth to superficial lamina (Tang et al., 2007). To determine whether Sox11 causes a similarly large displacement of connectivity, we compared the location of light-responsive units in intact and reinnervated spinal cord based on stereotactic positioning of recording electrodes 
A

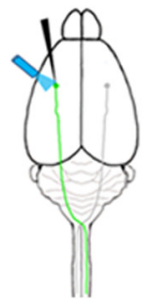

B

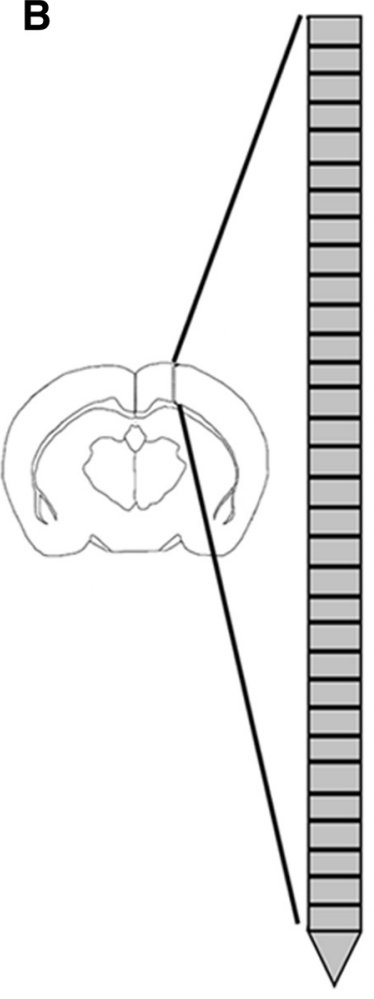

Position

Position 2

Position 3

Position 4

Position 5

Position 6

Position 7

Position 8

Position 9

Position 10

Position 11

Position 12

Position 13

Position 14

Position 15

Position 16

Position 17

Position 18

Position 19

Position 20

Position 21

Position 22

Position 23

Position 24

Position 25

Position 26

Position 27

Position 28

Position 29

Position 30

Position 31

Position 32
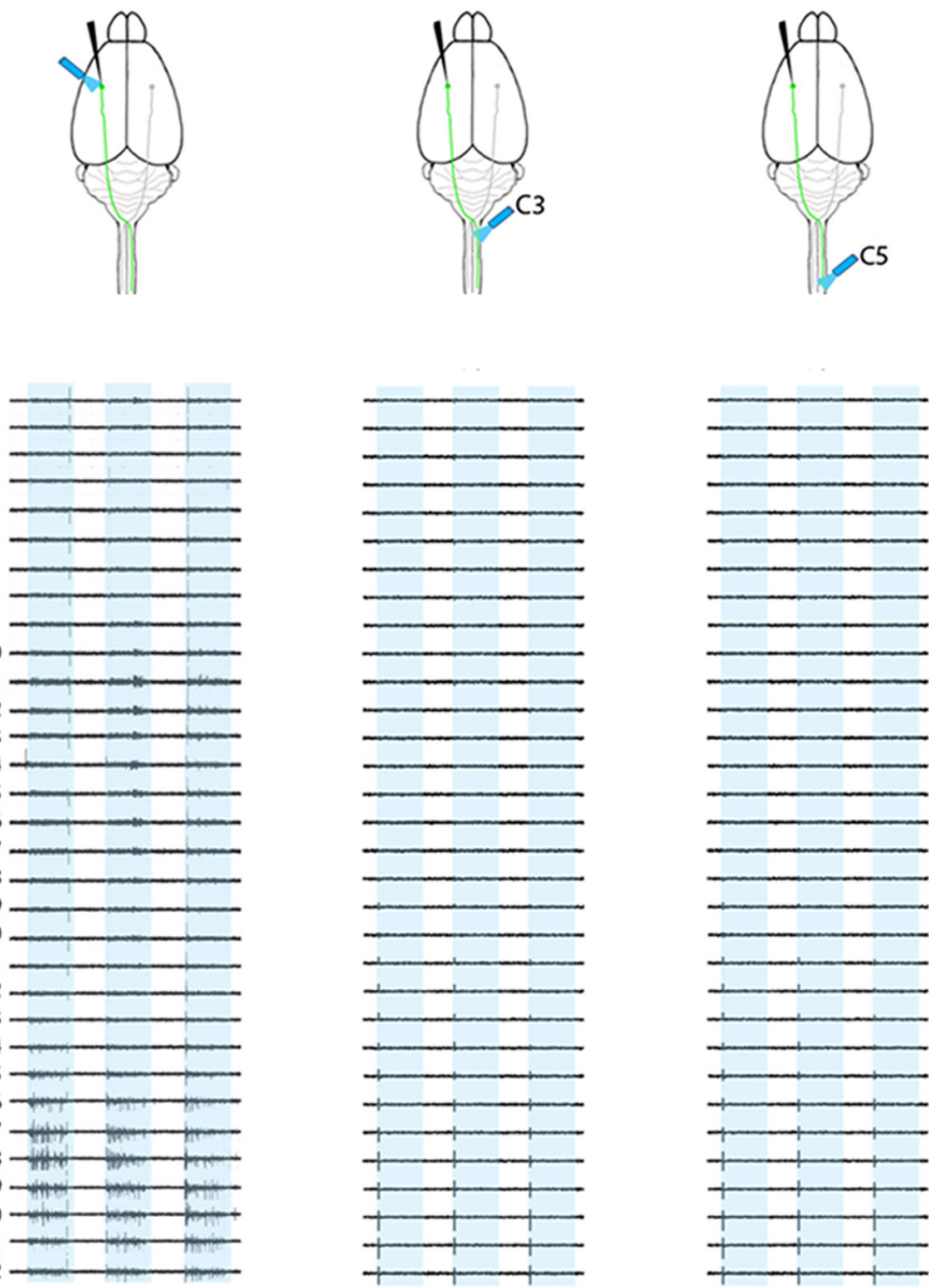

C

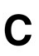

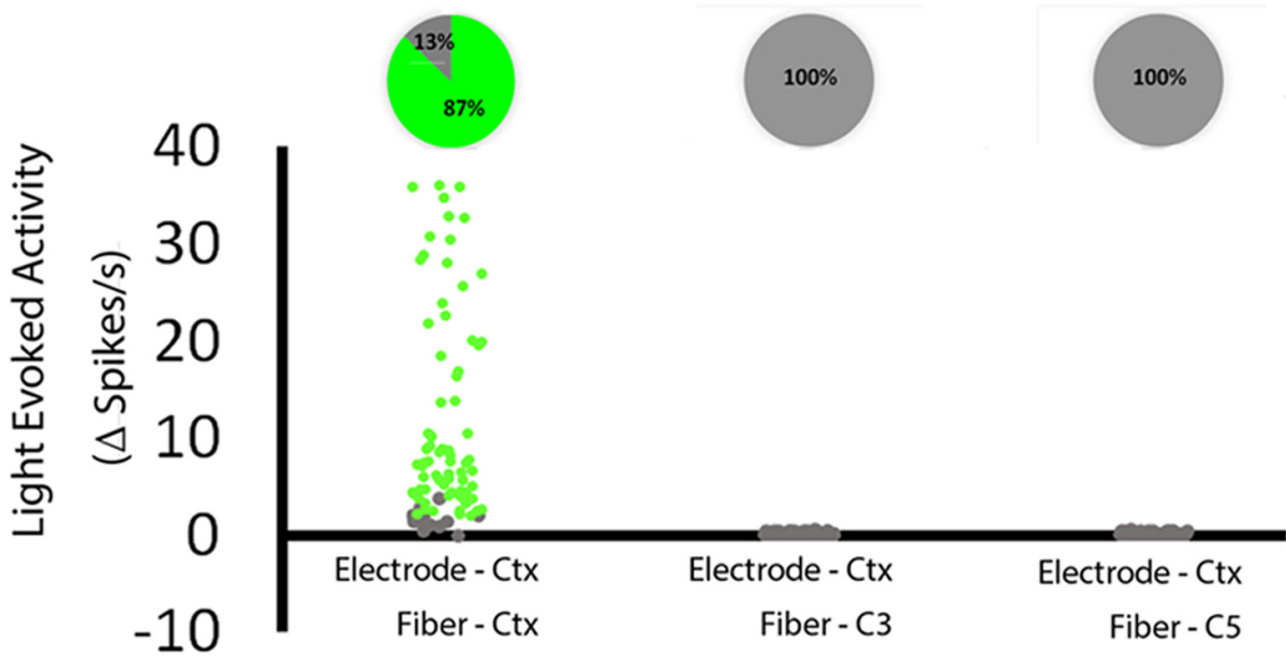

Figure 6. Optical stimulation of spinal CST axons does not result in antidromic activity in cortical cell bodies. Eight weeks after viral delivery of ChR2 to cortical neurons, the cortex was exposed to $473 \mathrm{~nm}$ light, and a recording electrode was positioned for maximal detection of light-evoked activity in transduced cell bodies. Without moving the electrode, C 3 and C5 spinal cord were exposed to light stimulation. $\boldsymbol{A}$, Schematic indicating positions of the recording electrode and light stimulation. $\boldsymbol{B}$, Examples of unit activity at multiple recording sites evoked by cell body, but not axonal, light stimulation. C, Pie charts show the percentage of cells that significantly increased firing rate during light stimulation. 0 92 units that showed significant light-evoked activity during light stimulation (green dots, $p$ values $<0.0001$, paired $t$ test), none showed significant responses to optical stimulation of spinal axons. $n=3$ animals, 92 recording positions. 
A

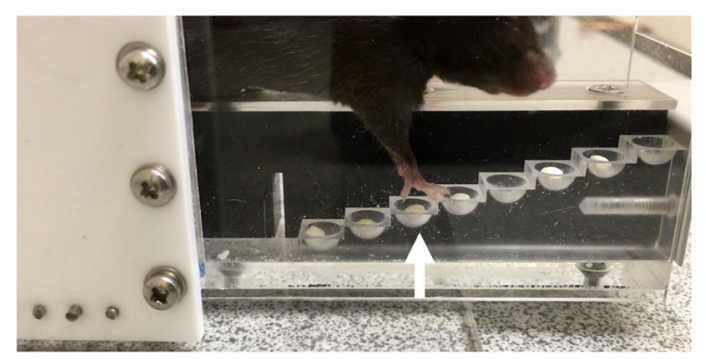

B

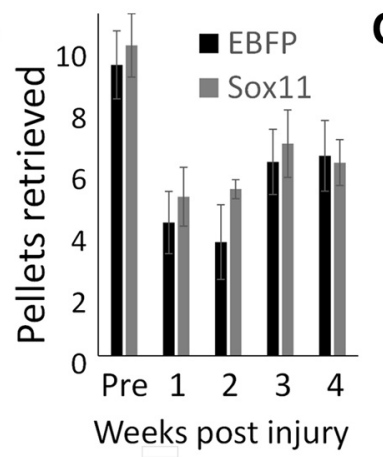

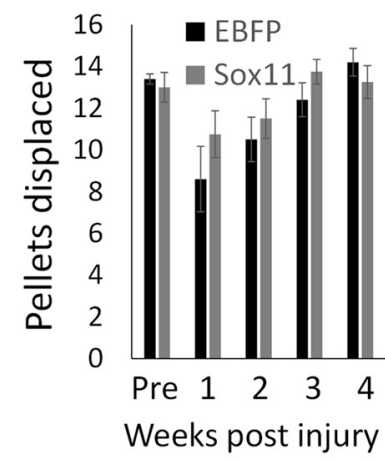

Figure 7. Viral overexpression of Sox11 in cortical neurons does not improve forelimb function in a pellet retrieval task. $\boldsymbol{A}$, Adult mice were pretrained on staircase pellet retrieval apparati, subjected to pyramidotomy and cortically injected with ChR2-EYFP and AAV-Sox11-2A-mCherry or AAV-EBFP-2A-mCherry control, and then tested weekly. $\boldsymbol{B}$, Injury caused a persistent reduction in the number of retrieved pellets that was unaffected by viral treatment, as was the total number of pellets displaced by reaching attempts ( $\boldsymbol{C} ; p>0.05,2$-way repeated-measures ANOVA with Bonferroni's post hoc test). $n=5$ animals per group.

relative to the dorsal spinal midline. Maps were generated to indicate the location of spontaneously active spinal units and color coded to indicate the percentage of animals in which units at that location displayed light-evoked increases in firing rate (Fig. 8). In the right (intact) cord of both EBFP control and Sox11-treated animals, light-evoked activity was most common in deeper recording sites along the electrode, corresponding approximately to lamina V-VIII (Fig. $8 A-D$ ). The same pattern was observed on the left side of Sox11-treated animals, with overall symmetry across the midline regarding the location of spinal units that responded to CST activation (Fig. $8 B, D$ ). Thus, within the limits of low spatial resolution of this approach, it appears that Sox11-stimulated CST axons that extend across the midline produce net spinal activity in locations that are similar to those found normally. These data suggest that, at the level of whole tissue, Sox11-stimulated axons establish functional connectivity in appropriate regions of spinal gray matter.

\section{Discussion}

Here we have adopted an optogenetic approach to monitor functional plasticity of axon terminals in the injured CNS. Using the corticospinal tract as a model system, we have determined the time course of ChR2 protein trafficking to axon terminals and confirmed the ability of direct optical stimulation to drive postsynaptic activity in contralateral cervical spinal cord. Using direct optogenetic stimulation, we also found that, after unilateral CST injury, the intact CST displays a very limited capacity to drive activity in the denervated half of the spinal cord. In contrast, CST axons stimulated to sprout across the spinal cord midline by forced expression of a pro-regenerative transcription factor drive robust postsynaptic activity. Control experiments verified that

this activity reflects direct synaptic input from the newly grown CST axon terminals, as opposed to relay circuits, a conclusion corroborated by the presence of synaptic proteins and absence of terminally evoked antidromic activity. These data illustrate the utility of optogenetics as a powerful diagnostic tool to monitor spontaneous and treatment-evoked plasticity in the injured CNS axons and demonstrate that genetically stimulated axons succeed in forming functional synapses.

Functional recovery from CNS damage ultimately depends not only on regenerative or compensatory axon growth but on the ability of newly grown axons to form functional synaptic connections that can evoke appropriate activity in the affected target fields. Notably, because various approaches have succeeded in promoting axon regeneration and sprouting after CNS injury, effects on animal behavior are at best partially beneficial (Liu et al., 2015; Zou et al., 2015) and can also be neutral (Lu et al., 2012a,b; Geoffroy et al., 2015) or even negative (Takeoka et al., 2011; Wang et al., 2015). Thus, the ability of growth-stimulated axons to synaptically integrate into target tissue is emerging as a key question in the field (Pernet and Schwab, 2014; Ramer et al., 2014).

Current techniques offer only partial insight into the ability of newly grown axons to make functional synapses that evoke postsynaptic activity. Immunohistochemistry is commonly used to colocalize synaptic proteins with axons of interest, but this approach alone can be only indicative of synapse function (Liu et al., 2010; Lu et al., 2014b; Du et al., 2015; Wu et al., 2015). To assess functional connectivity between cortex and spinal cord after spinal injury, a variety of transcranial or microstimulation methods to activate cell bodies or proximal axon tracts have been paired with monitoring of neuronal or muscle activity in distal locations (Fouad et al., 2001; Girgis et al., 2007; Cao et al., 2010; Iyer et al., 2010; Hunanyan et al., 2013; Tandon et al., 2013). Similarly, previous work has used optogenetic stimulation of cortical cell bodies to track injury-induced shifts in motor maps of forelimb movement (Harrison et al., 2012, 2013). Because cortical neurons can communicate with the spinal cord through a variety of relay circuits in the midbrain and brainstem (Z'Graggen et al., 2000; Alstermark et al., 2004; Nielsen et al., 2007; Krajacic et al., 2010; Siegel et al., 2015), it is challenging for these techniques to distinguish the contributions of the diverse inputs to the spinal cord or definitively assign function to sprouting cortical axons (but see Hunanyan et al., 2013). This makes it difficult to resolve the key question of the degree to which regenerated axons are effective in driving postsynaptic activity. One previous solution to this difficulty has been to perform retransection of tissue that contains regenerated axons and then testing for abrogation of previous gains in distal function (Takeoka et al., 2011; Lu et al., 2012b; Lee et al., 2013). This strategy shows any abrogated functions to have been the result of newly grown axons but still lacks the ability to resolve different information carried by diverse axon types that may have traversed the transected tissue. Finally, targeted chemogenetic silencing has emerged as an elegant approach to assign function to specific populations (Wahl et al., 2014; Siegel et al., 2015) but, because cells are silenced at the level of the cell body, does not resolve the question of whether the targeted cells transmit information directly or indirectly to target cells.

Here we find that terminal optogenetic stimulation, paired with extracellular single-unit recording, is an effective means to monitor functional integration by specific populations of newly grown axons. When stimulating cortical cell bodies, we noted that, as neurons increased expression of Chr2-EYFP in the weeks after viral injection, they showed increasing sensitivity to light 
stimulation, such that very low laser power became increasingly effective. Importantly, however, the total number of CST neurons that expressed ChR2 was stable between 4 and 8 weeks, as was their firing rate when exposed to optimal laser stimulation, indicating that $\mathrm{ChR} 2$ expression did not result in overt toxicity in CST neurons in this timeframe. Terminal stimulation of CST terminals in cervical spinal cord did not produce detectable antidromic activity in cortical cell bodies of origin, nor in contralateral spinal cord, the nearest site for potential antidromic relay. This finding is consistent with previous work indicating that optogenetic generation of antidromic activity is favored by proximity to the cell body and laser energy well above those used here (Tye et al., 2011; Ciocchi et al., 2015). However, terminal stimulation of CST axons stimulated to grow across the spinal midline did evoke significant increases in firing rate in nearby spinal neurons, which persisted even when terminals were isolated by midline transection. Thus, although these extracellular recordings are by their nature less definitive than intracellular (Hunanyan et al., 2013), the combined dataset offers strong evidence that Sox11-stimulated axons formed functional synapses in the previously denervated half of the spinal cord and that these synapses enabled effective modulation of postsynaptic activity. An important caveat is that the spinal responses are likely not all the result of monosynaptic input from the stimulated CST axons. Rather, the recorded activity is the sum both of direct CST input to a subset of neurons located in the zone of optical stimulation and local polysynaptic effects. In this regard, the output activity should be interpreted as the net effect of CST input to the tissue.

Consistent with our previous results, we find that forced Sox11 expression promotes sprouting of CST axons into denervated tissue in cervical spinal cord but that forelimb function is not detectably improved (Wang et al., 2015). In contrast, examples of spontaneous CST sprouting in injured primates and neonatal rodents show positive correlation with functional recovery, strongly implying successful functional connectivity (Z'Graggen et al., 2000; Rosenzweig et al., 2010). What might explain the difference? A potential concern for any pro-regenerative intervention, and particularly for the reactivation of early embryonic genes such as Sox11, is that the pro-regenerative treatment could potentially negatively affect synaptic function (Yan et al., 2009). In this context, the current data are illuminating because they rule out a general failure of synaptogenesis to explain the lack of behavioral improvement. Moreover, although the electrode mapping was at low resolution, to a first approximation, it also appears that tissue-level errors in postsynaptic targeting also do not occur. Finally, although failed myelination has been implicated in functional deficits in the regenerated optic system (Bei et al., 2016), CST collaterals in gray matter are not normally myelinated (Zukor et al., 2013), making it unlikely that myelination plays a regulating factor in the function of Sox11-stimulated sprouts.

Another possible explanation may be that the number of Sox11-stimulated sprouts, although substantial, remains suboptimal. Indeed, in a recent example in which genetically stimulated CST sprouting was associated with partial behavioral recovery, the degree of sprouting did appear to be greater than the Sox11 effect here (Jin et al., 2015). This high growth was achieved only with combinatorial genetic interventions, strongly motivating the search for factors that might synergistically increase the effect of Sox11 (Chandran et al., 2016). Another possibility is that, although we have now confirmed the overall ability of Sox11stimulated CST axons to drive postsynaptic activity, more subtle features of these new synapses (e.g., receptor density and composition) could still lower postsynaptic sensitivity to excitatory drive. Finally, it could also be that, although grossly normal at the tissue level, Sox11-stimulated CST axons may make errors in targeting appropriate subclasses of interneurons. Thus, an important future direction for research will be to compare interneuron subtypes targeted by intact versus newly grown CST axons. This explanation would also motivate efforts to reshape the pattern of synapses formed by newly growth CST axons; rehabilitative training in conjunction with Sox11-stimulated CST growth is an attractive option (Weishaupt et al., 2013). In summary, these results illustrate the utility of a paired optogenetic/electrophysiology approach to demonstrate functional connectivity by Sox11-stimulated axons, helping to direct attention to the need for strategies to improve fine tuning of the resulting synaptic function. 


\section{References}

Akbik F, Cafferty WB, Strittmatter SM (2012) Myelin associated inhibitors: a link between injury-induced and experience-dependent plasticity. Exp Neurol 235:43-52. CrossRef Medline

Alstermark B, Ogawa J, Isa T (2004) Lack of monosynaptic corticomotoneuronal EPSPs in rats: disynaptic EPSPs mediated via reticulospinal neurons and polysynaptic EPSPs via segmental interneurons. J Neurophysiol 91:1832-1839. CrossRef Medline

Baird AL, Meldrum A, Dunnett SB (2001) The staircase test of skilled reaching in mice. Brain Res Bull 54:243-250. CrossRef Medline

Balkaya M, Kröber JM, Rex A, Endres M (2013) Assessing post-stroke behavior in mouse models of focal ischemia. J Cereb Blood Flow Metab 33:330-338. CrossRef Medline

Barry JM (2015) Axonal activity in vivo: technical considerations and implications for the exploration of neural circuits in freely moving animals. Front Neurosci 9:153. CrossRef Medline

Bei F, Lee HH, Liu X, Gunner G, Jin H, Ma L, Wang C, Hou L, Hensch TK, Frank E, Sanes JR, Chen C, Fagiolini M, He Z (2016) Restoration of visual function by enhancing conduction in regenerated axons. Cell 164: 219-232. CrossRef Medline

Bernstein JG, Boyden ES (2011) Optogenetic tools for analyzing the neural circuits of behavior. Trends Cogn Sci 15:592-600. CrossRef Medline

Blackmore MG, Wang Z, Lerch JK, Motti D, Zhang YP, Shields CB, Lee JK, Goldberg JL, Lemmon VP, Bixby JL (2012) Kruppel-like Factor 7 engineered for transcriptional activation promotes axon regeneration in the adult corticospinal tract. Proc Natl Acad Sci U S A 109:7517-7522. CrossRef Medline

Bradbury EJ, Carter LM (2011) Manipulating the glial scar: chondroitinase $\mathrm{ABC}$ as a therapy for spinal cord injury. Brain Res Bull 84:306-316. CrossRef Medline

Cao Q, He Q, Wang Y, Cheng X, Howard RM, Zhang Y, DeVries WH, Shields CB, Magnuson DS, Xu XM, Kim DH, Whittemore SR (2010) Transplantation of ciliary neurotrophic factor-expressing adult oligodendrocyte precursor cells promotes remyelination and functional recovery after spinal cord injury. J Neurosci 30:2989-3001. CrossRef Medline

Chandran V, Coppola G, Nawabi H, Omura T, Versano R, Huebner EA, Zhang A, Costigan M, Yekkirala A, Barrett L, Blesch A, Michaelevski I, Davis-Turak J, Gao F, Langfelder P, Horvath S, He Z, Benowitz L, Fainzilber M, Tuszynski M, Woolf CJ, Geschwind DH (2016) A systemslevel analysis of the peripheral nerve intrinsic axonal growth program. Neuron 89:956-970. CrossRef Medline

Ciocchi S, Passecker J, Malagon-Vina H, Mikus N, Klausberger T (2015) Brain computation. Selective information routing by ventral hippocampal CA1 projection neurons. Science 348:560-563. CrossRef Medline

Du K, Zheng S, Zhang Q, Li S, Gao X, Wang J, Jiang L, Liu K (2015) Pten deletion promotes regrowth of corticospinal tract axons 1 year after spinal cord injury. J Neurosci 35:9754-9763. CrossRef Medline

Fink KL, Strittmatter SM, Cafferty WB (2015) Comprehensive corticospinal labeling with $\mu$-crystallin transgene reveals axon regeneration after spinal cord trauma in ngr1-/- mice. J Neurosci 35:15403-15418. CrossRef Medline

Fouad K, Pedersen V, Schwab ME, Brösamle C (2001) Cervical sprouting of corticospinal fibers after thoracic spinal cord injury accompanies shifts in evoked motor responses. Curr Biol 11:1766-1770. CrossRef Medline

Geoffroy CG, Lorenzana AO, Kwan JP, Lin K, Ghassemi O, Ma A, Xu N, Creger D, Liu K, He Z, Zheng B (2015) Effects of PTEN and Nogo codeletion on corticospinal axon sprouting and regeneration in mice. J Neurosci 35:6413-6428. CrossRef Medline

Girgis J, Merrett D, Kirkland S, Metz GA, Verge V, Fouad K (2007) Reaching training in rats with spinal cord injury promotes plasticity and task specific recovery. Brain 130:2993-3003. CrossRef Medline

Harrison TC, Ayling OG, Murphy TH (2012) Distinct cortical circuit mechanisms for complex forelimb movement and motor map topography. Neuron 74:397-409. CrossRef Medline

Harrison TC, Silasi G, Boyd JD, Murphy TH (2013) Displacement of sensory maps and disorganization of motor cortex after targeted stroke in mice. Stroke 44:2300-2306. CrossRef Medline

Harvey PA, Lee DH, Qian F, Weinreb PH, Frank E (2009) Blockade of Nogo receptor ligands promotes functional regeneration of sensory axons after dorsal root crush. J Neurosci 29:6285-6295. CrossRef Medline

Houle JD, Côté MP (2013) Axon regeneration and exercise-dependent plas- ticity after spinal cord injury. Ann N Y Acad Sci 1279:154-163. CrossRef Medline

Hunanyan AS, Petrosyan HA, Alessi V, Arvanian VL (2013) Combination of chondroitinase ABC and AAV-NT3 promotes neural plasticity at descending spinal pathways after thoracic contusion in rats. J Neurophysiol 110:1782-1792. CrossRef Medline

Iyer S, Maybhate A, Presacco A, All AH (2010) Multi-limb acquisition of motor evoked potentials and its application in spinal cord injury. J Neurosci Methods 193:210-216. CrossRef Medline

Jin D, Liu Y, Sun F, Wang X, Liu X, He Z (2015) Restoration of skilled locomotion by sprouting corticospinal axons induced by co-deletion of PTEN and SOCS3. Nat Commun 6:8074. CrossRef Medline

Kanda T, Sullivan KF, Wahl GM (1998) Histone-GFP fusion protein enables sensitive analysis of chromosome dynamics in living mammalian cells. Curr Biol 8:377-385. CrossRef Medline

Krajacic A, Weishaupt N, Girgis J, Tetzlaff W, Fouad K (2010) Traininginduced plasticity in rats with cervical spinal cord injury: effects and side effects. Behav Brain Res 214:323-331. CrossRef Medline

Lee DH, Luo X, Yungher BJ, Bray E, Lee JK, Park KK (2014) Mammalian target of rapamycin's distinct roles and effectiveness in promoting compensatory axonal sprouting in the injured CNS. J Neurosci 34:1534715355. CrossRef Medline

Lee JK, Geoffroy CG, Chan AF, Tolentino KE, Crawford MJ, Leal MA, Kang B, Zheng B (2010) Assessing spinal axon regeneration and sprouting in Nogo-, MAG-, and OMgp-deficient mice. Neuron 66:663-670. CrossRef Medline

Lee YS, Lin CY, Jiang HH, Depaul M, Lin VW, Silver J (2013) Nerve regeneration restores supraspinal control of bladder function after complete spinal cord injury. J Neurosci 33:10591-10606. CrossRef Medline

Lemon R (1984) Methods of neuronal recording in conscious animals. New York: Wiley.

Liske H, Qian X, Anikeeva P, Deisseroth K, Delp S (2013) Optical control of neuronal excitation and inhibition using a single opsin protein, ChR2. Sci Rep 3:3110. CrossRef Medline

Liu K, Lu Y, Lee JK, Samara R, Willenberg R, Sears-Kraxberger I, Tedeschi A, Park KK, Jin D, Cai B, Xu B, Connolly L, Steward O, Zheng B, He Z (2010) PTEN deletion enhances the regenerative ability of adult corticospinal neurons. Nat Neurosci 13:1075-1081. CrossRef Medline

Liu ZH, Yip PK, Adams L, Davies M, Lee JW, Michael GJ, Priestley JV, Michael-Titus AT (2015) A single bolus of docosahexaenoic acid promotes neuroplastic changes in the innervation of spinal cord interneurons and motor neurons and improves functional recovery after spinal cord injury. J Neurosci 35:12733-12752. CrossRef Medline

Lu P, Blesch A, Graham L, Wang Y, Samara R, Banos K, Haringer V, Havton L, Weishaupt N, Bennett D, Fouad K, Tuszynski MH (2012a) Motor axonal regeneration after partial and complete spinal cord transection. J Neurosci 32:8208-8218. CrossRef Medline

Lu P, Wang Y, Graham L, McHale K, Gao M, Wu D, Brock J, Blesch A, Rosenzweig ES, Havton LA, Zheng B, Conner JM, Marsala M, Tuszynski MH (2012b) Long-distance growth and connectivity of neural stem cells after severe spinal cord injury. Cell 150:1264-1273. CrossRef Medline

Lu P, Kadoya K, Tuszynski MH (2014a) Axonal growth and connectivity from neural stem cell grafts in models of spinal cord injury. Curr Opin Neurobiol 27:103-109. CrossRef Medline

Lu P, Woodruff G, Wang Y, Graham L, Hunt M, Wu D, Boehle E, Ahmad R, Poplawski G, Brock J, Goldstein LS, Tuszynski MH (2014b) Longdistance axonal growth from human induced pluripotent stem cells after spinal cord injury. Neuron 83:789-796. CrossRef Medline

Lüscher C, Pascoli V, Creed M (2015) Optogenetic dissection of neural circuitry: from synaptic causalities to blue prints for novel treatments of behavioral diseases. Curr Opin Neurobiol 35:95-100. CrossRef Medline

Moore DL, Blackmore MG, Hu Y, Kaestner KH, Bixby JL, Lemmon VP, Goldberg JL (2009) KLF family members regulate intrinsic axon regeneration ability. Science 326:298-301. CrossRef Medline

Nielsen JB, Perez MA, Oudega M, Enriquez-Denton M, Aimonetti JM (2007) Evaluation of transcranial magnetic stimulation for investigating transmission in descending motor tracts in the rat. Eur J Neurosci 25:805814. CrossRef Medline

Onifer SM, Smith GM, Fouad K (2011) Plasticity after spinal cord injury: relevance to recovery and approaches to facilitate it. Neurotherapeutics 8:283-293. CrossRef Medline 
Pernet V, Schwab ME (2014) Lost in the jungle: new hurdles for optic nerve axon regeneration. Trends Neurosci 37:381-387. CrossRef Medline

Petreanu L, Mao T, Sternson SM, Svoboda K (2009) The subcellular organization of neocortical excitatory connections. Nature 457:1142-1145. CrossRef Medline

Ramer LM, Ramer MS, Bradbury EJ (2014) Restoring function after spinal cord injury: towards clinical translation of experimental strategies. Lancet Neurol 13:1241-1256. CrossRef Medline

Rosenzweig ES, Courtine G, Jindrich DL, Brock JH, Ferguson AR, Strand SC, Nout YS, Roy RR, Miller DM, Beattie MS, Havton LA, Bresnahan JC, Edgerton VR, Tuszynski MH (2010) Extensive spontaneous plasticity of corticospinal projections after primate spinal cord injury. Nat Neurosci 13:1505-1510. CrossRef Medline

Siegel CS, Fink KL, Strittmatter SM, Cafferty WB (2015) Plasticity of intact rubral projections mediates spontaneous recovery of function after corticospinal tract injury. J Neurosci 35:1443-1457. CrossRef Medline

Smith GM, Falone AE, Frank E (2012) Sensory axon regeneration: rebuilding functional connections in the spinal cord. Trends Neurosci 35:156163. CrossRef Medline

Starkey ML, Barritt AW, Yip PK, Davies M, Hamers FP, McMahon SB, Bradbury EJ (2005) Assessing behavioural function following a pyramidotomy lesion of the corticospinal tract in adult mice. Exp Neurol 195:524539. CrossRef Medline

Stuber GD, Sparta DR, Stamatakis AM, van Leeuwen WA, Hardjoprajitno JE, Cho S, Tye KM, Kempadoo KA, Zhang F, Deisseroth K, Bonci A (2011) Excitatory transmission from the amygdala to nucleus accumbens facilitates reward seeking. Nature 475:377-380. CrossRef Medline

Takeoka A, Jindrich DL, Muñoz-Quiles C, Zhong H, van den Brand R, Pham DL, Ziegler MD, Ramón-Cueto A, Roy RR, Edgerton VR, Phelps PE (2011) Axon regeneration can facilitate or suppress hindlimb function after olfactory ensheathing glia transplantation. J Neurosci 31:42984310. CrossRef Medline

Tandon S, Kambi N, Mohammed H, Jain N (2013) Complete reorganization of the motor cortex of adult rats following long-term spinal cord injuries. Eur J Neurosci 38:2271-2279. CrossRef Medline

Tang XQ, Heron P, Mashburn C, Smith GM (2007) Targeting sensory axon regeneration in adult spinal cord. J Neurosci 27:6068-6078. CrossRef Medline

Terzuolo CA, Araki T (1961) An analysis of intra- versus extracellular potential changes associated with activity of single spinal motoneurons. Ann N Y Acad Sci 94:547-558. Medline

Tye KM, Prakash R, Kim SY, Fenno LE, Grosenick L, Zarabi H, Thompson
KR, Gradinaru V, Ramakrishnan C, Deisseroth K (2011) Amygdala circuitry mediating reversible and bidirectional control of anxiety. Nature 471:358-362. CrossRef Medline

Ueno M, Hayano Y, Nakagawa H, Yamashita T (2012) Intraspinal rewiring of the corticospinal tract requires target-derived brain-derived neurotrophic factor and compensates lost function after brain injury. Brain 135:1253-1267. CrossRef Medline

Wahl AS, Omlor W, Rubio JC, Chen JL, Zheng H, Schröter A, Gullo M, Weinmann O, Kobayashi K, Helmchen F, Ommer B, Schwab ME (2014) Neuronal repair. Asynchronous therapy restores motor control by rewiring of the rat corticospinal tract after stroke. Science 344:1250-1255. CrossRef Medline

Wang Z, Reynolds A, Kirry A, Nienhaus C, Blackmore MG (2015) Overexpression of Sox11 promotes corticospinal tract regeneration after spinal injury while interfering with functional recovery. J Neurosci 35:31393145. CrossRef Medline

Weishaupt N, Li S, Di Pardo A, Sipione S, Fouad K (2013) Synergistic effects of BDNF and rehabilitative training on recovery after cervical spinal cord injury. Behav Brain Res 239:31-42. CrossRef Medline

Weishaupt N, Mason AL, Hurd C, May Z, Zmyslowski DC, Galleguillos D, Sipione S, Fouad K (2014) Vector-induced NT-3 expression in rats promotes collateral growth of injured corticospinal tract axons far rostral to a spinal cord injury. Neuroscience 272:65-75. CrossRef Medline

Wu D, Klaw MC, Connors T, Kholodilov N, Burke RE, Tom VJ (2015) Expressing constitutively active Rheb in adult neurons after a complete spinal cord injury enhances axonal regeneration beyond a chondroitinase-treated glial scar. J Neurosci 35:11068-11080. CrossRef Medline

Yan D, Wu Z, Chisholm AD, Jin Y (2009) The DLK-1 kinase promotes mRNA stability and local translation in C. elegans synapses and axon regeneration. Cell 138:1005-1018. CrossRef Medline

Z'Graggen WJ, Fouad K, Raineteau O, Metz GA, Schwab ME, Kartje GL (2000) Compensatory sprouting and impulse rerouting after unilateral pyramidal tract lesion in neonatal rats. J Neurosci 20:6561-6569. Medline

Zou Y, Stagi M, Wang X, Yigitkanli K, Siegel CS, Nakatsu F, Cafferty WB, Strittmatter SM (2015) Gene-silencing screen for mammalian axon regeneration identifies Inpp5f (Sac2) as an endogenous suppressor of repair after spinal cord injury. J Neurosci 35:10429-10439. CrossRef Medline

Zukor K, Belin S, Wang C, Keelan N, Wang X, He Z (2013) Short hairpin RNA against PTEN enhances regenerative growth of corticospinal tract axons after spinal cord injury. J Neurosci 33:15350-15361. CrossRef Medline 